\begin{tabular}{|c|c|c|}
\hline $\begin{array}{l}\text { MAY } \\
\text { sta } 4: 500\end{array}$ & ENGINEERING DATA TRANSMITTAL & 1. EDT $\quad 628740$ \\
\hline
\end{tabular}

2. To: (Receiving (organization)

RPP Characterization Engineering

5. Proj./Prog./I)ep./Div.:

Characterization Project

3. From: (Originating Organization)

RPP Characterization Engineering

6. Design Authority/Design Agent/Cog. Engr.

GP Janicek/RN Dale

8. Originator Remark:

This EDT releases the Operations and Maintenance (O \& M) Manual for the

LLCERS RT and TT.

11. Receiver Remarks: 11A. Design Baseline Document? || Yes [X]No

4. Related EDT No.:
\[ \text { N/A } \]
7. Purchase Order No.:
9/A Equip./Component No.:
N/A

10. System/Bldg./Facility:

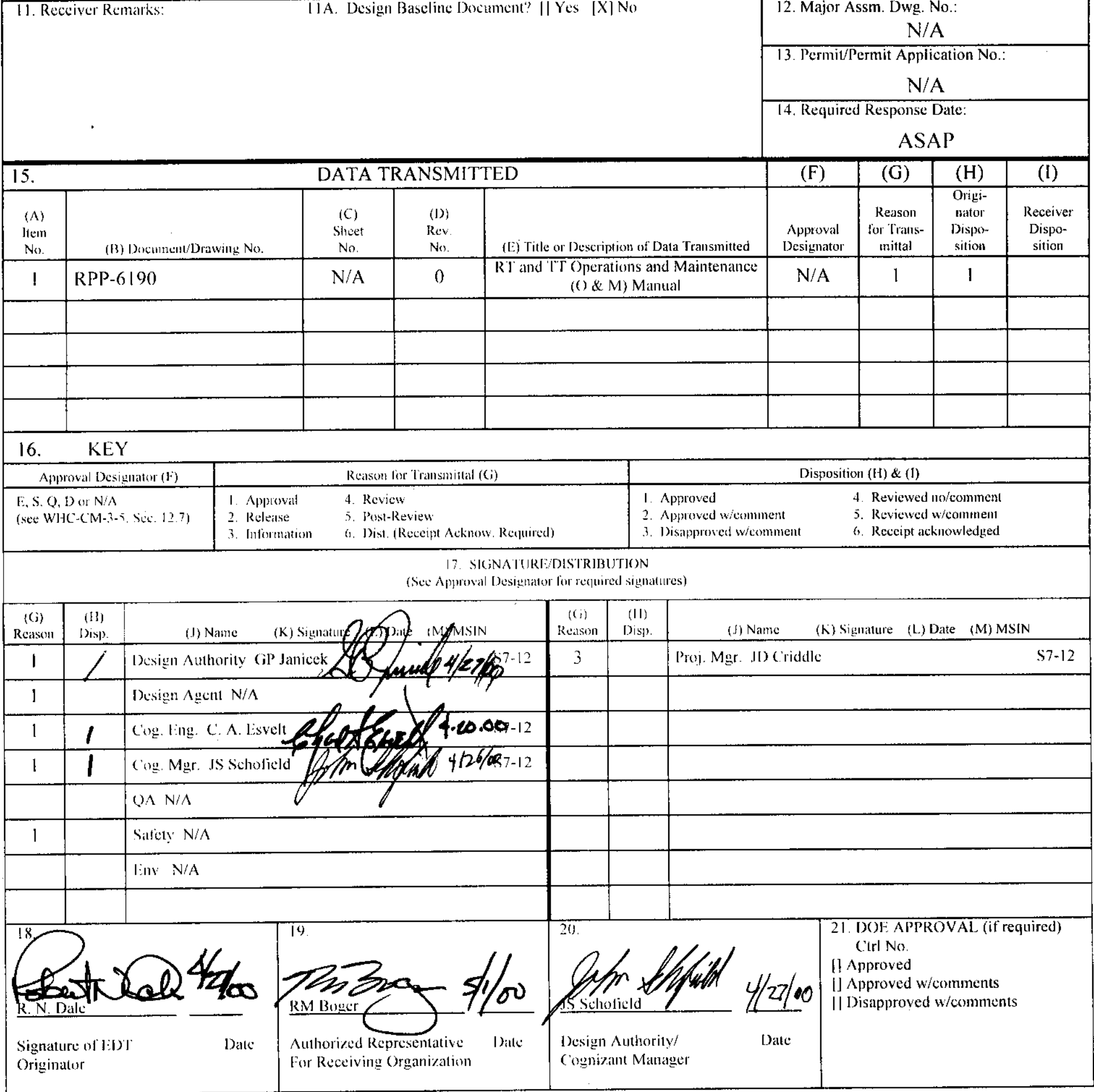

BD-7400-172-2(05/96) (il:Fo97 


\title{
LONG LENGTH CONTAMINATED EQUIPMENT RETREIVAL. SYSTEM RECEIVER TRAILER AND TRANSPORT TRAILER OPERATIONS AND MAINTENANCE MANUAL
}

\author{
R. N. Dale \\ Prepared by CH2MHILL Hanford Group, Inc. \\ Richland, WA 99352 \\ U.S. Department of Energy Contract DE-AC06-96RL13200

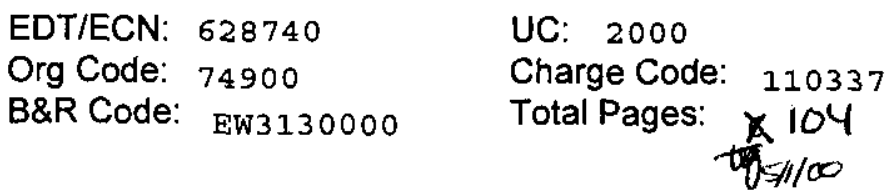

Key Words: LLCERS Receiver Trailer, Transport Trailer, o \& M Manual

Abstract: This document contains the $O \& M$ Manual for the LLCERS Receiver and Transport Trailer.

\footnotetext{
TRADEMARK DISCLAIMER. Reference herein to any specific commercial product, process, or service by trade name, trademark, manufacturer, or otherwise, does not necessarily constitute or imply its endorsement, recommendation, or favoring by the United States Government or any agency thereof or its contractors or subcontractors.

Printed in the United States of America. To obtain copies of this document, contact: Document Control Services, P.O. Box 950, Mailstop H6-08, Richland WA 99352, Phone (509) 372-2420; Fax (509) 376-4989.
}
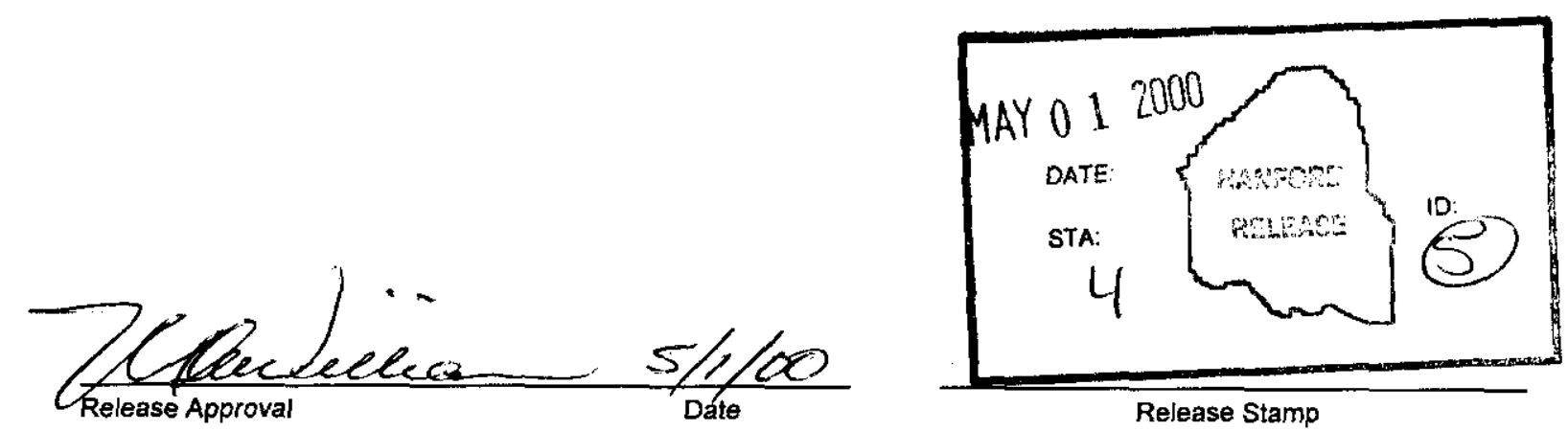

Approved For Public Release 
RPP-6190, Rev. 0

\title{
LONG LENGTH CONTAMINATED EQUIPMENT RETREIVAL SYSTEM RECEIVER TRAILER AND TRANSPORT TRAILER OPERATIONS AND MAINTENANCE MANUAL
}

\author{
Prepared for CH2M Hill Hanford Group, Inc. \\ Characterization Field Engineering Group \\ By \\ G. P. Janicek and R. N. Dale \\ CH2M HILL Hanford Group, Inc.
}

April, 2000 


\section{TABLE OF CONTENTS}

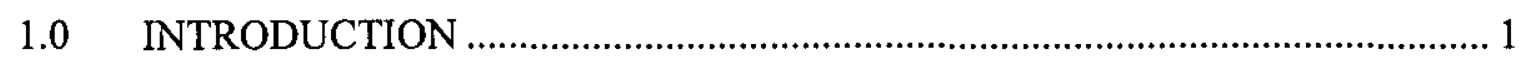

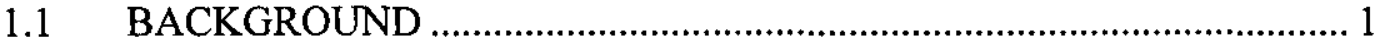

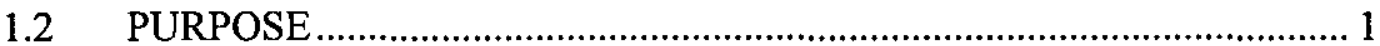

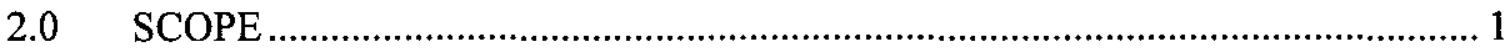

3.0 GENERAL DESIGN DESCRIPTION ........................................................ 1

4.0 OPERATIONS AND MAINTENANCE MANUAL

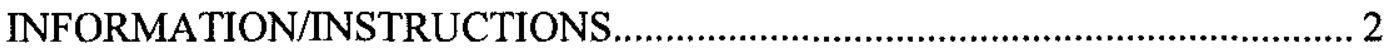

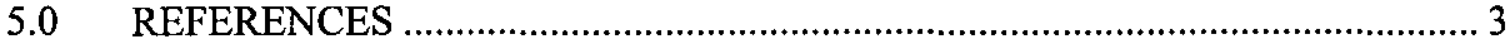

APPENDIX A......................................................... A 


\section{LONG LENGTH CONTAMINATED EQUIPMENT RETREIVAL SYSTEM RECEIVER TRAILER AND TRANSPORT TRAILER OPERATIONS AND MAINTENANCE MANUAL}

\subsection{INTRODUCTION}

\subsection{BACKGROUND}

A system to accommodate the removal of long-length contaminated equipment (LLCE) from Hanford underground radioactive waste storage tanks was designed, procured, and demonstrated, via a project activity during the 1990s. The system is the Long Length Contaminated Equipment Removal System (LLCERS). LLCERS will be maintained and operated by Tank Farms Engineering and Operations organizations and other varied projects having a need for the system. The responsibility for the operation and maintenance of the LLCERS Receiver Trailer (RT) and Transport Trailer (TT) resides with the RPP Characterization Project Operations organization.

\subsection{PURPOSE}

The purpose of this document is to provide vendor supplied operating and maintenance $(\mathrm{O} \& \mathrm{M})$ information for the RT and TT in a readily retrievable form. This information is provided this way instead of in a vendor information (VI) file to maintain configuration control of the operations baseline as described in RPP-6085, "Configuration Management Plan for Long Length Contaminated Equipment Receiver and Transport Trailers". Additional Operations Baseline documents are identified in RPP- 6085 .

\subsection{SCOPE}

The LLCERS is composed of a number of separate components acting together for the purpose of removing LLCE from Hanford nuclear waste tanks. This document is only applicable to the LLCERS Receiver Trailer (RT) and the Transport Trailer (TT) that were procured in the mid 1990s per procurement specification WHC-S-0321, Rev. 0.

\subsection{GENERAL DESIGN DESCRIPTION}

LLCE to be removed from underground waste tank risers is expected to range in length from 12 feet to 55 feet. Actual removal will be performed using cranes dedicated to tank farm service. Coincident with removal of the LLCE from the tank riser the LLCE will be covered with a plastic sleeve and tied at each end to confine any radioactive or toxic contamination remaining after decontamination spray washing. The crane will then transport the LLCE to the skid on the RT. 
The RT is outfitted with a "skid and strong back" to receive the contained LLCE. The skid is locked onto the strong back which is hydraulically raised and lowered to interface with the crane. It is placed in the raised, vertical, position to receive the LLCE from the crane, and is then lowered to a horizontal position in conjunction with the lowering of the LLCE by the crane. The RT is also outfitted with a winch driven "tug" that transfers the LLCE onto the TT. The function of the tug is to push the contained LLCE and skid from on-board the RT into the burial container on board the TT. The RT is aligned and leveled to mate with the TT to perform this operation.

The TT is outfitted with a structure, (chocks and tie down ratchet straps), that holds a burial container into which the LLCE package is placed. Once the LLCE package is transferred from the RT to the burial container the container is sealed. Then the TT transports the LLCE package to a storage or burial site, for removal by another crane.

\subsection{OPERATIONS AND MAINTENANCE MANUAL INFORMATION/INSTRUCTIONS}

The information and instructions, presented in this document, are for the operation and maintenance of the LLCERS RT and TT. Appendix A of this document is an exact replica (without appendices) of the vendor supplied O \& M manual, "LLCE TRAILERS OPERATION AND MAINTENANCE MANUAL". The appendices of the vendor supplied O \& M manual contain a drawing tree (included in RPP-6189, "Long Length Contaminated Equipment Retreival System Trailers Drawings", for configuration control) and vendor equipment cut sheets . The information in RPP-6190 will be utilized as guidance in preparation of specific operating and maintenance procedures for the RT and TT Trailers.

The vendor supplied $\mathrm{O} \& \mathrm{M}$ manual (including appendices) is incorporated into Vendor Information (VI) file 22809 which will be maintained in the Hanford Document Control System. The VI file will be maintained for historical purposes only, i.e., to document the precise materials and component configuration received from the vendor in response to the procurement specification for the RT and TT 
RPP-6190, Rev. 0

\subsection{REFERENCES}

WHC 1995, Specification for the Handling and Transport of Tanks Farms Long-Length Contaminated Equipment - WHC-S-0321, Rev. 0, Westinghouse Hanford Company, Richland, Washington.

CHG 2000a, Long Length Contaminated Equipment Retreival System Trailers Drawings - RPP-6189, CH2MHILL Hanford Group, Inc., Richland, Washington.

CHG 2000b, "Configuration Management Plan for Long Length Contaminated Equipment Receiver and Transport Trailers", RPP-6085, Richland, Washington. 


\section{Appendix A}

\section{Operation and \\ Maintenance Manual}

\section{LLCE Trailers}

Mobilized Systems, Inc. 
Operation and Maintenance Manual Revision A

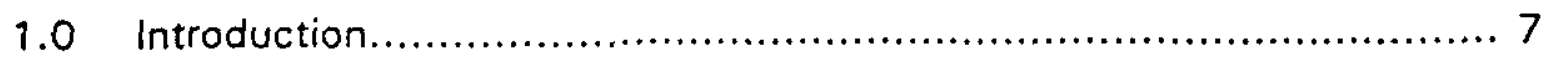

2.0 Description of Equipment.............................................. 7

2.1 Receiver Trailer (TL8001-01)................................... 7

2.1.1 Electrical System......................................... 7

2.1.2 Hydraulic System.......................................... 8

2.1 .3 Maneuverability System.................................. 8

2.1.4 Outriggers (Stabilization Jacks) ......................... 8

2.1.5 Tug and Winch System..................................... 8

2.1.6 Video Camera Systems..................................... 8

2.1.7 Generator Power System................................ 9

2.1 .8 Skid....................................................... 9

2.1.9 Strongback................................................ 9

2.1.10 Front Wall Shielding ........................................ 9

2.1.11 Forward End Restraint installation on Transport

Trailer Deck................................................ 10

2.2 Transport Trailer (TL8002-01) .................................. 10

2.2.1 Electrical System.......................................... 10

2.2 .2 Hydraulic System......................................... 11

2.2.3 Maneuverability System.................................... 11

2.2.4 Outriggers (Stabilization Jacks)............................ 11

2.2.5 Strap Latch Control System................................ 11

2.2.6 Generator Power System................................. 12

2.2.7 Front End Restraint......................................... 12

2.2.8 Chock Assemblies........................................... 12

2.2 .9 Side Wall Shielding........................................... 13

2.2.10 Front Wall Shielding...................................... 13

2.3 Trailer Specifications................................................ 14

2.3.1 Receiver Trailer (TL8001-01) ............................... 14

2.3.2 Transport Trailer (TL8002-01) ............................. 14

2.3.3 Skid Diameter Sizes....................................... 15

2.4 Definitions.................................................... 15

3.0 Documentation................................................... 16

3.1 Receiver Trailer Drawing Tree...................................... 16

3.2 Transport Traiter Drawing Tree..................................... 16

3.3 Codes and Standards used for Construction of Trailers............ 16

3.3.1 Revised Code of Washington............................... 16

3.3.2 Code of Federal Regulations (CFR) ...................... 16

3.3.3 American institute fo Steel Construction.................... 17 
Operation and Maintenance Manual Revision $\mathrm{A}$

3.3.4 American National Standards Institute (ANSI).............. 17

3.3.5 American Society for Nondestructive Testing (ANST)..... 17

3.3.6 American Society of Civil Engineer.s (ASCE)................ 18

3.3.7 American Society of Mechanical Engineers (ASME)........ 18

3.3.8 American Welding Society (AWS) ........................... 18

3.3.9 Factory Mutual (FM) ......................................... 18

3.3.10 Military Standards....................................... 18

3.3.11 National Electrical Manufacturing Association (NEMA)... 18

3.3.12 National Fire Protection Association (NFPA).............. 18

3.3.13 Society of Automotive Engineers (SAE) ................... 19

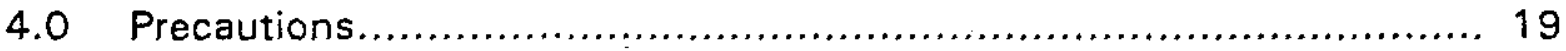

4.1 Personnel Precaution Areas.................................... 20

4.1.1 Receiver Trailer Areas and Special Instructions.............. 20

4.1.2 Transport Trailer Areas and Special Instrucitons............. 21

4.2 Equipment Precautions......................................... 22

5.0 Preparation of Operation of Transport and Packaging System........... 22

5.1 Receiver Trailer Laydown Yard Setup................................ 22

5.1.1 Power Source Selection (reference DWG 8001E page 3).. 22

5.1 .2 Generator Operation.......................................... 22

5.1.2.1 Starting ............................................. 22

5.1.2.1 Generator Power Check............................ 22

5.1.3 Tug Direction - Forward/Reverse........................... 24

5.1.4 Pusher - Forward/Reverse.................................. 25

5.1.5 Skid Installation................................................ 25

5.1.5.1 Skid Common Interface Installation.................. 25

5.1.5.2 Rigging Guide Installation........................... 26

5.1.5.3 Positioning Skid Lower Guide Wheels............... 26

5.1.5.4 Lifting and Handling of Skid......................... 26

5.1.5.5 Positioning of Skid in Strongback................... 27

5.1.5.6 Strongback Guide Wheel Positioning................ 28

5.1.5.7 Skid Alignment Fixture............................... 29

5.1.5.8 Skid Plug Installation................................ 29

5.1.5.9 Recheck Plug Installation............................ 29

5.1.6 Coupling Tractor to Receiver Trailer.......................... 29

5.1.7 RV Video System............................................ 30

5.1.9 Hydraulics Start-Up........................................ 31

5.1.10 IR Remote Control Start-Up............................... 31

5.1.10.7 IR Remote Control Function Checkout............. 32 
Operation and Maintenance Manual Revision A

5.1.10.7.1 Undercarriage - Lock/Release............ 32

5.1.10.7.2 Level-Up/Down \& Jack Select.......... 32

5.1.10.7.3 Slide-Left/Right \& Slide Select.......... 33

5.1.10.7.6 Strongback Motion \& Strongback Direction-Up/Down........................ 34

5.1 .10 .7 .7 E-Stop................................... 34

5.1 .10 .7 .8 Steering Right/Left........................ 35

5.1.11 Receiver Trailer Setup Checklist..................... 38

5.2 Transport Trailer Setup (TL8002-01)......................... 38

; $\quad 5.2 .1$ Power Source Selection................................. 38

5.2 .2 Generator Operation................................ 38

5.2.2.1 Starting.................................. 39

5.2.2.2 Generator Power Check................. 40

5.2.3 Laser Alignment System Installation/Calibration.... 40

5.2.4 Install Burial Container Chocks........................ 41

5.2.5 Lifting Beam Rigging for Burial Container............. 41

5.2.6 Position Beam in Supports............................ 41

5.2.7 Install Hydraulic Cylinders on Chocks................. 42

5.2.8 Tie-down/Tarp Installation............................ 42

5.2.9 Checklist for Movement............................... 44

5.2.10 Coupling Tractor to Trailer............................ 45

5.3 Cold Trailer Alignment....................................... 45

5.3.2 Uncoupling the Tractor................................ 45

5.3.3 Shore Power/Connection Test....................... 46

5.4 Receiver Trailer Tank Farm Checkout/Setup................. 47

5.4.1 Park Receiver Trailer..................................... 47

5.4.2 Uncouple Tractor................................... 47

5.4.3 Shore Power Connection/Test.......................... 48

5.4.4 Pendant Control Connection............................ 50

5.4.5 Pendant Control Function Checkout.................... 50

5.4.5.1 Undercarriage Lock/Rèlease............. 50

5.4.5.2 Level-Up/Down \& Jack Select.......... 51

5.4.5.3 Slide-Left/Right \& Slide Select.......... 52

5.4.5.4 Tug Direction - Forward/Reverse....... 53

5.4.5.5 Pusher - Forward/Release................ 54

5.4.5.6 Strongback Motion \& Strongback

Direction-Up/Down....................... 54

5.4.5.7 Leveling.................................... 55

5.4.6 Elevation Angle Indicator............................. 56

5.4 .7 Video Systems..................................... 56 
Operation and Maintenance Manual Revision A

5.4.7.1 LLCE Handling Video System.......... 57

5.4.8 IR Remote Control Startup............................. 57

5.4.8.7 IR Remote Control Function Checkout. 58

5.4.8.7.1 Undercarriage-Lock/Release....... 58

5.4.8.7.2 LEVEL-UP/DOWN \& Jack Select.. 58

5.4.8.7.3 SLIDE-LEFT/RIGHT\& Slide Selelct..59

5.4.8.7.6 STRONGBACK MOTION \&

STRONGBACK DIRECTION-

UP/DOWN......................... 60

$5.4 .8 .7 .7 \quad$ E-STOP........................... 61

5.4.8.7.8 STEERING RIGHT/LEFT......... 61

5.5 Transport Trailer System Checkout........................... 64

5.5.1 Shore Power Connection/Test....................... 64

5.5.2 Pendant Control Connection........................... 65

5.5.3 Pendant Control Function Checkout.................. 66

5.5.3.1 Undercarriage-Lock/Release..............66 66

5.5.3.2 Level-Up/Down \& Jack Select.......... 66

5.5.3.3 Slide-Left/Right \& Slide Select..........67 67

5.5.3.4 Strap Latch/Release...................... 68

5.5.4 IR Remote Control Startup............................ 69

5.5.5 IR Remote Control Function Checkout................ 70

5.5.5.1 Undercarriage-Lock/Release............. 70

5.5.5.2 Level-Up/Down \& Jack Select.......... 70

5.5.5.3 Slide-Left/Right \& Slide Select.......... 71

5.5.5.4 Strap Latch/Release..................... 72

5.5.5.5 Steer Right/Left......................... 72

6.0 Operation Sequence of Trailer Systems................................... 75

6.1 Transport Trailer.................................................. 75

6.2 Receiver Trailer........................................................ 75

6.3 Dock \& Load...................................................... 76

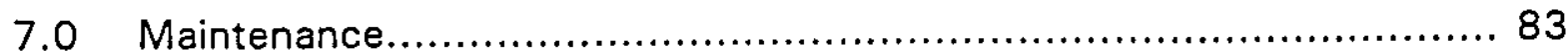

7.1 Scheduled Maintenance Items Table ............................... 83

7.3 Adjustments and Alignment..................................... 89

7.4 Calibration Requirements and Procedures......................... 91

8.0 Trouble Shooting................................................................ 91

8.1 Receiver Trailer....................................................... 91

8.1 .1 PROBLEM: NO PROBLEM ................................. 91 
Operation and Maintenance Manual Revision A

8.1.2 PROBLEM: NO CONTROL..................................... 92

8.1.3 PROBLEM: UNDERCARRIAGE FUNCTION NOT WORKING.92

8.1.4 PROBLEM: LEVEL UP/DOWN NOT WORKING................ 92

8.1.5 PROBLEM: JACK SELECT NOT WORKING .................. 92

8.1.6 PROBLEM: SLIDE NOT WORKING.......................... 93

8.1.7 PROBLEM: TUG NOT WORKING.............................. 93

8.1.8 PROBLEM: PUSHER NOT WORKING........................ 93

8.1.9 PROBLEM: STRONG BACK NOT WORKING................ 94

8.1.10 PROBLEM: STEERING ..................................... 94

8.1.11 PROBLEM: HYDRAULICS NOT WORKING................. 94

8.1.12 PROBLEM: UTILITY FUNCTIONS NOT WORKING......... 94

8.2 Transport Trailer.................................................. 94

8.2.1 PROBLEM: NO POWER ...................................... 95

8.2.2 PROBLEM: NO CONTROL.................................. 95

8.2.3 PROBLEM: UNDERCARRIAGE FUNCTION NOT WORKING.95

8.2.4 PROBLEM: LEVEL UP/DOWN NOT WORKING............... 95

8.2.5 PROBLEM: JACK SELECT NOT WORKING.................... 95

8.2.6 PROBLEM: SLIDE NOT WORKING............................ 96

8.2.7 PROBLEM: STRAP NOT WORKING....................... 96

8.2.8 PROBLEM: STEERING NOT WORKING..................... 96

8.2.9 PROBLEM: HYDRAULICS NOT WORKING................. 96

9.1 List of Major Components and Source............................. 97

Appendix A: $\quad$ Receiver Trailer Drawing Tree............................... 99

Appendix B: $\quad$ Transport Trailer Drawing Tree............................ 100

Appendix C: $\quad$ Fabrication Documentation................................... 101

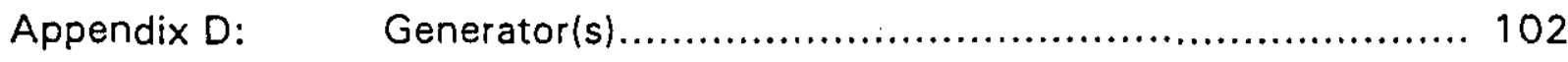

Appendix E: $\quad$ Duff Norton Jacks........................................... 103

Appendix F: $\quad$ Eagle Equipment Hydraulics Information...................... 104

Appendix G: $\quad$ Video Cameras............................................. 105 
Operation and Maintenance Manual Revision A

1.0 Introduction

Below is a brief description of the trailers and their respective major components or systems. The steps involved in operating these systems will be discussed in detail in the Operations section of this manual.

\subsection{Description of Equipment}

The LLCE retrieval is a multi-step process with interrelated and independent functions being accomplished with a universal system. The equipment provided by MSl includes two trailers accompanied by all necessary support items.

2.1 Receiver Trailer (TL8001-01)

The Receiver trailer is parked at the site where the item is to be pulled out of the tank. The item is craned out of the tank and hung vertically on the vertical Strongback frame of the trailer. The item is lowered back to the horizontal position and is readied to push into the burial container resting on the Transport trailer at another location.

Refer to Appendix A for the Receiver Trailer Drawing Tree

\subsubsection{Electrical System}

The Electrical system of the Receiver Trailer (TL8001-01) is designed to operate on the $480 \mathrm{~V}$ Delta connected power available on the Hanford site.

The power source is selectable between Site Power and on-board Generator Power.

\subsubsection{Hydraulic System}

The Hydraulic system of the Receiver Trailer consists of dual pumps, a 200 gallon reservoir, supply and return filters and the necessary valving to perform the control functions.

The components used on both systems are identical to make sparing of parts easier. 
Operation and Maintenance Manual Revision A

\subsubsection{Maneuverability System}

The trailer has a steerable undercarriage assembly. Steering is accomplished by electrically controlled hydraulic valves. Power for the hydraulic system and the electrical controls required for steering is derived from the on-board generator. The actual steering commands are given via the IR control transmitter.

\subsubsection{Outriggers (Stabilization Jacks)}

The trailer is fitted with electrically powered screw jacks located approximately at the four corners of the trailer. Control of these jacks is selectable to allow the trailer to be leveled and then elevated to operational position. The jacks have limit switches appropriately located to prevent overtravel. Additionally, there is a stop collar on each jack screw that will mechanically limit over travel.

\subsubsection{Tug and Winch Systems}

The Receiver trailer has a mobile device called a TUG which is propelled down the length of the trailer by an electrically powered winch. The Tug runs in a track. The tug is used to move the LLCE and skid into the burial container located on the Transport trailer. Located on the tug is an additional screw jack. This jack is attacked to a coupling device which is used to provide the final 24 " of travel to insert the LLCE fully into the burial container. The tug is interlocked with the Strongback control such that the Strongback cannot be lifted unless the turg is in its home position. The tug is also interlocked to prevent it moving unless the Strongback is in its full lowered position.

\subsubsection{Video Camera Systems}

The Receiver trailer has two separate video systems. The first is used for docking the two trailers. This system consists of an RV style camera located at the rear of the trailer, and a video monitor that may be located in the cab of the tractor connected to the trailer. The second system incorporates two cameras, a pan/tilt mount and control and a remote mounted video monitor enclosure. 
Operation and Maintenance Manual Revision A

\subsubsection{Generator Power System}

The Receiver Trailer has an on-board 20KW Diesel Generator to supply AC power for the hydraulic power supply in order that the trailer may be remotely steered during transport of the contaminated equipment. The AC power is also used to power the $I R$ control receiver and the electrical controls. The generator is intended to provide power during transit but can be used in limited capacity to operate the other systems in an emergency.

The generator on the Receiver Trailer is sufficient to operate one of the two hydraulic pumps. This is adequate to provide steering power. The generator will power one elevation jack at a time or both front and rear slide motors.

\subsubsection{Skid}

The skid is a consumable steel half-pipe used for transferring the LLCE horizontally from the receiver trainer into a burial container, which is mounted on the Transport trailer. The skid protects the flexible receiver bag from tearing and provides containment of liquid waste if a breach occurs. The skid is attached to the Strongback on the forward end and can be remotely disconnected to allow the horizontal transfer into the burial container to occur.

\subsubsection{Strongback}

The Strongback lowers the LLCE from a vertical to horizontal position. It supports the skid and rotates on a trunnion located at the aft end of the trailer. Remotely operated hydraulic cylinders are used to ensure a controlled lowering of the LLCE.

\subsubsection{Front Wall Shielding}

Removable radiation shielding is installed on the front of the trailer to provide shielding for the driver while the trailer is being moved from within the tank farm boundary to the area where the LLCE transfer occurs. 
Operation and Maintenance Manual

Revision A

\subsubsection{Forward End Restraint Installation on Transport Trailer Deck}

An end restraint is provided at the front end of the burial container to provide a stop for a severe forward movement of the burial container. The end restraint can be located for restraint of both the $70 \mathrm{ft}$. and $52 \mathrm{ft}$. burial containers. It also has adjustment for an 8 " reweld length reduction of the container at both of the locations. There are two bolts that hold the assembly to the trailer deck, mainly to keep the assembly from tipping over if impacted from the side (ie crane rigging). Chains are provided for both the normal container length and the shorter "reweld" container length. If there is a need to restrain a rewelded container, a new shorter set of chains must be taken out of storage and installed. Be sure to locate the 3/4" diameter chains at the top two positions and the $1 / 2$ " diameter chains in the bottom positions. The load binders and shackles are common to both chain sets. There are different numbers of chains to anchor to the chock depending on which chock is being installed ( 5 lengths per side). Always start at the bottom with the $1 / 2$ " chains and work your way up. If there are three holes in the chock, as an example, then the three bottom $1 / 2$ " chains are installed. If there are four holes in the chock, then the three $1 / 2$ " chains and one 3/4" chain is installed, and so on.

\subsection{Transport Trailer (TL8002-01)}

The transport trailer is loaded with a burial container which receives the contaminated item from the receiver trailer. As the item enters the burial container, it is resting in a half-round steel shell. Once the item is pushed into the burial container, an end cap is put on and the container is filled with void fill material. The container is then craned off of the trailer and buried in a specially lined hole.

\subsubsection{Electrical System}

The Electrical system of the Transport Trailer (TL8002-01) is designed to operate on the $480 \mathrm{~V}$ Delta connected power available on the Hanford site.

The power source is selectable between Site Power and on-board Generator Power. 
Operation and Maintenance Manual Revision A

\subsubsection{Hydraulic System}

The Hydraulic system of the Transport Trailer consists of a single pump, a 40 gallon reservoir, supply and return filters and the necessary valving to perform the control functions.

The components used on both systems are identical to make sparing of parts easier.

\subsubsection{Maneuverability System}

The Transport Trailer has a steerable undercarriage assembly. Steering is accomplished by electrically controlled hydraulic valves. Power for the hydraulic system and the electrical controls required for steering is derived from the on-board generator. The actual steering commands are given via the IR control transmitter.

\subsubsection{Outriggers (Stabilization Jacks)}

The Transport Trailer is fitted with electrically powered screw jacks located approximately at the four corners of the trailer. Control of these jacks is selectable to allow the trailer to be leveled and then elevated to operational position. The jacks have limit switches appropriately located to prevent overtravel. Additionally, there is a stop collar on each jack screw that will mechanically limit over travel.

The trailer is equipped with remotely operated outrigger assemblies that allow the trailer to function on uneven ground. The outriggers have a number of functions including raising, leveling, and "skewing" to allow proper axial alignment of the two trailers prior to skid insertion

\subsubsection{Strap Latch Control System}

The transport Trailer has an electrical/hydraulic system to release the latching cylinders that hold the tie down straps in position. The latch cylinders are spring loaded to the extended position to provide a fail safe latched state. Hydraulic pressure must be applied to release the latches. A manual pump is included that will provide pressure in the event of electrical failure. 
Operation and Maintenance Manual Revision A

\subsubsection{Generator Power System}

The Transport Trailer has an on-board 20KW Diesel Generator to supply AC power for the hydraulic power supply in order that the trailer may be remotely steered during transport of the contaminated equipment. The AC power is also used to power the $I R$ control receiver and the electrical controls. The generator is intended to provide power during transit but can be used in limited capacity to operate the systems in an emergency.

The generator on the Transport Trailer is sufficient to operate the hydraulic pump. This is adequate to provide steering power. The generator will power one elevation jack at a time or both front and rear slide motors.

\subsubsection{Front End Restraint}

An end restraint is provided at the front end of the burial container to provide a stop for a severe forward movement of the burial container. The end restraint can be located for restraint of both the $70 \mathrm{ft}$. and $52 \mathrm{ft}$. burial containers. It also has adjustment for an 8 " reweld length reduction of the container.

\subsubsection{Chock Assemblies}

The Transport trailer is equipped with five different sizes of full length chocks for the five different diameters of burial containers. The chocks are split into nominal $52 \mathrm{ft}$. and $18 \mathrm{ft}$. sections to mate with the various container lengths. Each chock is equipped with its own set of tie-down straps to anchor the burial container to the full length chock. These straps are remotely released via spring loaded hydraulic cylinders to release the burial container from the chock when off-loading the container. The sizes and respective weights of each chock section are listed below. 
Operation and Maintenance Manual Revision A

\begin{tabular}{|c|c|}
\hline Chock Size & $\begin{array}{c}\text { Total Weight (lbs) } \\
\text { (Note that CG is dead center) }\end{array}$ \\
\hline $26 "-18 \mathrm{ft}$. Section & 734 \\
\hline $26 "-52 \mathrm{ft}$. Section & 2166 \\
\hline $36 "-18 \mathrm{ft}$. Section & 1000 \\
\hline $36 "-52 \mathrm{ft}$. Section & 3000 \\
\hline $54 "-18 \mathrm{ft}$. Section & 1400 \\
\hline $54^{\prime \prime}-52 \mathrm{ft}$. Section & 4600 \\
\hline $63^{\prime \prime}-18 \mathrm{ft}$. Section & 1600 \\
\hline $63^{\prime \prime}-52 \mathrm{ft}$. Section & 5400 \\
\hline $72 "-70 \mathrm{ft}$. Section & 8000 \\
\hline
\end{tabular}

\subsubsection{Side Wall Shielding}

The Transport trailer is equipped with $1 / 2$ " thick steel shield walls along the sides of the unit to provide personnel protection from radiation. These walls are removable via lift rings which are threaded into the top of each section.

\subsubsection{Front Wall Shielding}

Three layers of 1 " steel are installed on the front of the trailer to provide a total of 3 " of protection for the driver with the payload on board. These shield walls are also removable if the need exists. 
Operation and Maintenance Manual Revision A

\subsection{Trailer Specifications}

\subsubsection{Receiver Trailer (TL8001-01)}

Trailer Dimensions: 82'-6" Long

$160 \mathrm{y} / 2$ " Wide (outside of outrigger jacks)

174 " Tall (high point is front shield wall)

Trailer Weight: $\quad 106,420$ lbs. On Rear Suspension

(Unloaded)

$$
\text { 16,153 lbs. On King Pin }
$$

122,573 lbs. Total Weight (Empty 54 " skid on board \& no (tem)

Trailer Weight: $\quad 123,317$ lbs. On Rear Suspension

(Fully Loaded)

21,625 lbs. On King Pin

144,942 lbs. Total Weight (with 26,238 \# item on board)

Turn Radius: $\quad 48 \mathrm{ft} .3^{\prime \prime}$

Grade Variation: $8 \%$

Capability

\subsubsection{Transport Trailer (TL8002-01)}

Trailer Dimensions: $76^{\prime}-0^{\prime \prime}$ Long

$160 \mathrm{y} / 2$ " Wide (outside of outrigger jacks)

175" Tall (high point is front end support)

Trailer Weight: $\quad 97,340$ lbs. On Rear Suspension

(Unloaded) 35,054 lbs. On King Pin

132,394 ibs. Total Wt. 154" Chock w/Empty Container on board)

Trailer Weight: $\quad 165,000$ lbs. On Rear Suspension (Fully Loaded)

56,643 lbs. On King Pin

$221,643 \mathrm{lbs}$. Total Weight (with 26,238 \# item and grout fill)

Turn Radius: $\quad 48 \mathrm{ft} .3^{\prime \prime}$

Grade Variation: $8 \%$

Capability 
Operation and Maintenance Manual Revision A

\subsubsection{Skid Diameter Sizes}

The Receiver trailer is capable of loading five (5) different skid diameters depending on the size of the item being pulled. Below is a list of the skid sizes and their usable inside widths and lengths.

\begin{tabular}{|c|c|l|c|}
\hline Skid Number & $\begin{array}{c}\text { Nominal Distance } \\
\text { Between Pipes } \\
\text { (Internal Width) }\end{array}$ & \multicolumn{1}{|c|}{ Internal Length } & $\begin{array}{c}\text { Skid } \\
\text { Weight lbs. }\end{array}$ \\
\hline 26 & $16.39^{\prime \prime}$ & $\begin{array}{l}827.38 \text { (for Long } \\
\text { Containers) } \\
632.38 \text { (for Short } \\
\text { Containers) }\end{array}$ & 2600 \\
\hline 36 & $25.40^{\prime \prime}$ & $\begin{array}{l}827.38 \text { (for Long } \\
\text { Containers) } \\
632.38 \text { (for Short } \\
\text { Containers) }\end{array}$ & 3200 \\
\hline 54 & $42.10^{\prime \prime}$ & $\begin{array}{l}827.38 \text { (for Long } \\
\text { Containers) } \\
632.38 \text { (for Short } \\
\text { Containers) }\end{array}$ & 2250 \\
\hline 63 & $50.91^{\prime \prime}$ & $\begin{array}{l}827.38 \text { (for Long } \\
\text { Containers) } \\
632.38 \text { (for Short } \\
\text { Containers) }\end{array}$ & 3125 \\
\hline 71 & & $\begin{array}{l}827.38 \text { (Long Containers } \\
\text { only) }\end{array}$ & 5000 \\
\hline
\end{tabular}

\subsection{Definitions}

\subsubsection{LEFT}

Looking at the rear of the trailer, LEFT moves the rear of the trailer toward the Roadside. The forward end of the Transport trailer remains essentially stationary and only pivots slightly on the outriggers. The forward end of the Receiver trailer is powered and will move in the direction opposite the rear of the trailer. 
Operation and Maintenance Manual Revision A

\subsubsection{RIGHT}

Looking at the rear of the trailer, RIGHT moves the rear of the trailer toward the Curbside. The forward end of the Transport trailer remains essentially stationary and only pivots slightly on the outriggers. The forward end of the Receiver trailer is powered and will move in the direction opposite the rear of the trailer.

2.4.3 UP

The term UP is used to indicate motion of the trailer in the upward direction.

\subsubsection{DOWN}

The term DOWN is used to indicate motion of the trailer in a downward direction.

3.0 Documentation

3.1 Receiver Trailer Drawing Tree

See Appendix A

3.2 Transport Trailer Drawing Tree

See Appendix B

3.3 Codes and Standards used for Construction of Trailers

3.3.1 Revised Code of Washington

46.37, "Vehicle Lighting and Other Equipment" 46.44, "Size, Weight, Load"

\subsubsection{Code of Federal Regulations (CFR)}

29 CFR 1910, "General Industry Safety, Occupational Safety and Health Administration (OSHA)"

49 CFR 172, Appendix C, "Dimensional Specifications for Recommended Placard Holder"

49 CFR 393, "Parts and Accessories Necessary for Safe Operation" 
Operation and Maintenance Manual Revision A

49 CFR 566, "Manufacturer Identification"

49 CFR 567, "Certification"

49 CFR 571, "Federal Motor Vehicle Safety Standards"

Federal Motor Vehicle Safety Standards (FMVSS)

FMVSS-106, "Brake Hose"

FMVSS-108, "Lamps, Reflective Devices, and Associated Equipment"

FMVSS-115, "Vehicle Identification Number"

FMVSS-119, "New Pneumatic Tires for Vehicles Other Than Passenger Cars"

FMVSS-120, "Tire Selection and Rims for Motor Vehicles Other Than Passenger Cars"

FMVSS-121, "Air Brake System"

\subsubsection{American Institute of Steel Construction}

"Specification for Structural Joints Using ASTM A325 or A490 Bolts" "Steel Construction Manual, Allowable Stress Design, Current Edition"

\subsubsection{American National Standards Institute (ANSI)}

ANSI/NFP(A) T2.24.1, "Hydraulic Fluid Power--Systems Standard for Stationary Industrial Machinery" (National Fluid Power Association)

ANSI A58.1, "Building Code Requirements for Minimum Design Loads in Buildings and other Structures"

ANSI C84.1, "Electrical Power System and Equipment--Voltage Ratings 60 $\mathrm{Hz}-1989^{\prime \prime}$

\subsubsection{American Society for Nondestructive Testing (ASNT)}

ASNT SNT-TC-LA based upon the nondestructive examination requirements 
Operation and Maintenance Manual Revision A

3.3.6 American Society of Civil Engineers (ASCE)

ASCE 7-88, "Minimum Design Loads for Buildings and Other Structures"

3.3.7 American Society of Mechanical Engineers (ASME)

B30.7-1989, "Base Mounted Drum Hoists"

3.3.8 American Welding Society (AWS)

ANSI/AWS 01.1, "Structural Welding Code - Steel".

ANSI/AWS D9.1, "Sheet Metal Welding Code"

QCl-88, "Standard for Qualification and Certification of Welding Inspectors"

3.3.9 Factory Mutual (FM)

"Approval Guide 1993 Edition"

3.3.10 Military Standards

MIL-STD-1472D, Section 5.3

MIL-STD-889

3.3.11 National Electrical Manufacturing Association (NEMA)

Publication 250, "Enclosures for Electrical Equipment (1000 V Maximum)" ICS 1, "General Standards for Industrial Control and Systems"

ICS 6, Rev. 1, "Enclosures for Industrial Controls and Systems"

3.3.12 National Fire Protection Association (NFPA)

NFPA 70, "National Electrical Code" 
Operation and Maintenance Manual Revision A

\section{NOTE}

NFPA 70 does not directly apply to mobile systems (Article 90-2(b)(1)). Mobilized Systems, Inc. is in compliance with the intent of the articles of the code.

\subsubsection{Society of Automotive Engineers (SAE)}

J133, "Fifth Wheel Kingpin Performance--Commercial Trailers and Semitrailers"

J214, "Hydraulic Cylinder Test Procedure"

J318, "Air Brake Gladhand Service (Control) and Emergency (Supply) Line Couplers--Truck, Truck-Tractors, and Trailers"

J560, "Seven-Conductor Electrical Connector for Truck-Trailer Jumper Cable"

J588, "Turn Signal Lamps"

J682, "Rear Wheel Splash and Stone Throw Protection"

J700, "Fifth Wheel Kingpin--Commercial Trailers and Semitrailers"

J701, "Truck Tractor Semitrailer Interchange Coupling Dimensions"

J702, "Brake and Electrical Connection Locations--Truck-Tractor and

Truck-Trailer"

J1292, "Automobile, Truck, Truck-Tractor, Trailer, and Motor Coach Wiring"

\section{J429, "Graded Fasteners"}

\subsection{Precautions}

Due to the nature of the trailer systems it is recommended that all personnel working in the area strictly adhere to on-site safety rules and regulations. This may include wearing a hard hat, safety glasses, steel toed shoes, etc. Below are some key areas where safety is of particular concern. 
Operation and Maintenance Manual Revision A

\subsection{Personnel Precaution Areas}

4.1.1 Receiver Trailer Areas and Special Instructions

\begin{tabular}{|l|l|}
\hline \multicolumn{1}{|c|}{ Precaution Area } & \multicolumn{1}{|c|}{ Special Instructions } \\
\hline 1. Outrigger feet & $\begin{array}{l}\text { Keep feet clear of outriggers as } \\
\text { the foot pad makes contact } \\
\text { with the ground }\end{array}$ \\
\hline 2. Tug area & $\begin{array}{l}\text { Be aware of the motion of the } \\
\text { tug. Also note that there are } \\
\text { winch cables in this area which } \\
\text { may present a tripping hazard. }\end{array}$ \\
\hline $\begin{array}{l}\text { 3. Skid ball Hitch connection } \\
\text { area }\end{array}$ & $\begin{array}{l}\text { Keep hands clear as the } \\
\text { Strongback-to-skid jack pins are } \\
\text { being actuated. Also keep clear } \\
\text { of the ball hitch as it comes } \\
\text { down over the ball }\end{array}$ \\
\hline 4. Skid Guide Wheels (4 & $\begin{array}{l}\text { Do not sit in the skid as it is } \\
\text { being pushed down line (ie: a } \\
\text { practice run). } \\
\text { locations) } \\
\text { guids may be severed by the } \\
\text { the pipe on top of either side of } \\
\text { the half-round skid. }\end{array}$ \\
\hline 5. Alignment Laser Beam & $\begin{array}{l}\text { Do not look directly into the } \\
\text { laser beam being projected from } \\
\text { the transport trailer. }\end{array}$ \\
\hline
\end{tabular}


Operation and Maintenance Manual

Revision A

4.1.2 Transport Trailer Areas and Special Instructions

\begin{tabular}{|l|l|}
\hline \multicolumn{1}{|c|}{ Precaution Area } & \multicolumn{1}{|c|}{ Special Instructions } \\
\hline 1. Outrigger feet & $\begin{array}{l}\text { Keep feet clear of outriggers as } \\
\text { the foot pad makes contact } \\
\text { with the ground }\end{array}$ \\
\hline 2. Front end restraint & $\begin{array}{l}\text { Note that the end restraint is } \\
\text { craned into place. Stay clear of } \\
\text { this area as the assembly is } \\
\text { being lowered into place. }\end{array}$ \\
\hline 3. Chock/Deck area & $\begin{array}{l}\text { Note that the Chocks are also } \\
\text { craned into place. Stay clear of } \\
\text { this area as the assemblies are } \\
\text { being craned into place. }\end{array}$ \\
\hline 4. Strap Cylinders & $\begin{array}{l}\text { Keep fingers clear of hydraulic } \\
\text { strap cylinder pins. The pins are } \\
\text { pushed into place by a spring. }\end{array}$ \\
\hline 5. Bogey Capture Assembly & $\begin{array}{l}\text { The bogey of this trailer is } \\
\text { equipped with a hydraulic } \\
\text { device that captures the } \\
\text { forward bogey in order to keep } \\
\text { the trailer going straight when } \\
\text { being pulled. Stay clear of this } \\
\text { area when the device is being } \\
\text { actuated. Chains are provided } \\
\text { for this area to keep personnel } \\
\text { from taking a short-cut under } \\
\text { the trailer to get to the other } \\
\text { side. }\end{array}$ \\
\hline 6. Shield at the Rear End & $\begin{array}{l}\text { A personnel protection shield } \\
\text { has been provided on each } \\
\text { chock assembly to minimize } \\
\text { radiation dosages when working } \\
\text { at the open end of the burial } \\
\text { container. }\end{array}$ \\
\hline
\end{tabular}


Operation and Maintenance Manual Revision A

\subsection{Equipment Precautions}

\section{Note:}

In order to not risk damaging the equipment due to low temperatures, it is necessary to heat the hydraulic oil prior to use. The system does have a heater for this purpose, however it does take a fair amount of time to arrive at the proper temperature. The recommended operating temperature for the oil is approximately 90 deg.F. A thermometer is built into the system for monitoring. If time is of the essence, both hydraulic pumps can be used to also heat the oil, provided the oil temperature is 50 degrees $F$ or above.

\subsection{Preparation for Operation of Transport and Packaging System}

The LLCE handling system requires an initial setup before each use. The proper Chock, Burial Container and Skid combination must be installed and all operational systems must be checked for functionality.

5.1 Receiver Trailer Laydown Yard Setup (after long term storage $>3$ months)

The Electrical system of the Receiver Trailer (TL8001-01) is designed to operate on the $480 \mathrm{~V}$ Delta connected power available on the Hanford site.

\subsubsection{Power Source Selection (reference DWG 8001E page 3)}

Located inside the lefthand control box is the power source selector switch, TRSW1. Position 1 selects input from an external source, the center position is a neutral or OFF position and position 2 selects the On-Board generator as the power source. Select on board generator if shore power is unavailable for laydown yard.

\subsubsection{Generator Operation (reference DWG 8001E page 3)}

\subsubsection{Starting}

The generator may be started from either of two locations. The first is a control box located on the right front of the engine. It contains an ON/OFF switch, a Glow Plug heat switch, a Glow Plug indicator, an hour meter and an engine start button. The second is remotely located near the electrical control boxes on the roadside of the trailer. 
Operation and Maintenance Manual Revision A

The starting sequence using the engine mounted controls is:

1. Set the toggle switch located at the top of the panel to the $O N$ position.

2. If the ambient temperature is below $40^{\circ} \mathrm{F}$, press and hold the Glow Plug button. Observe the glow plug located on the panel, when it begins to glow red, release the button. If the temperature is above $40^{\circ} \mathrm{F}$ it is usually not necessary to preheat the glow plugs.

3. Press the Start button. The engine should start after a brief period of cranking. If the engine does not start immediately, release the Start button, wait 30 seconds and try again.

4. If the engine will not start, see the manufacturer's manual in Appendix $D$ for further instructions.

The starting sequence using the remote mounted controls is:

1. Insert the key into the ignition switch.

2. If the ambient temperature is below $40^{\circ} \mathrm{F}$, turn the key $\mathrm{CCW}$ and hold for no longer than 15 seconds. If the temperature is above $40^{\circ} \mathrm{F}$ it is usually not necessary to preheat the glow plugs.

3. Turn the key fully $\mathrm{CW}$ to the Start position, hold in this position until the engine starts but no longer than 10 seconds in the event that the engine does not start.

4. When engine starts, release the key, it will move to the RUN position.

5. If the engine does not start, see the manufacturer's manual for instructions found in the electrical section of the product literature binder supplied by Mobilized Systems, Inc. 
Operation and Maintenance Manual Revision A

\subsubsection{Generator Power Check}

Reference Drawing No. $8001 \mathrm{E}$ for Electrical reference.

5.1.2.2.1 Set POWER SOURCE SELECTOR switch, TSRW1, to the GENERATOR (2) position.

5.1.2.2.2 In Control Box 1, set CB2 to its $O N$ position.

5.1.2.2.3 In Control Box 1, set CB1 to its ON position.

5.1.2.2.4 Observe the LEDs located on the power monitor, neither should be illuminated. CB1 should remain in its $\mathrm{ON}$ position.

5.1.3 Tug Direction - Forward / Reverse

\section{NOTE}

For the purposes of this functional test the skid must not be in place on the Strongback.

5.1.3.1 Lift and move the TUG DIRECTION switch (SW9) to the REVERSE position. Connect $P 5$ to $J 5$ and $P 3$ to $J 3$ on the front roadside of the trailer. Run the TUG toward the rear of the trailer approximately $2 \mathrm{ft}$. in preparation for testing the TUG's forward travel and stopping via the limit switching.

5.1.3.2 Lift and move the TUG DIRECTION switch to the FORWARD position. The tug shall move to its full forward position (nose of the trailer), the TUG PARKED light (DS6) on the control box will illuminate.

5.1.3.3 Insert P5 into J5 (Pusher Power) and P3 into J3 (Pusher Limit Switches).

5.1.3.4 Lift and move the TUG DIRECTION switch to the REVERSE position. The tug shall not move.

5.1.3.5 Disconnect P5 from J5 (Pusher Power) and P3 from J3 (Pusher Limit Switches).

5.1.3.6 Turn the TUG DIRECTION switch (SW9) to the REVERSE position. The tug shall move to its full AFT position (rear of the trailer), the TUG PARKED light (DS6) on the control box will extinguish as soon as the tug begins to move. 
Operation and Maintenance Manual Revision A

It is not necessary to run the tug the full length of the trailer to verify functional operation of tug.

Return the tug to its parked position and insert P5 into $J 5$ Pusher power and P3 into J3 for pusher limit switch testing.

\subsubsection{Pusher - Forward / Reverse}

5.1.4.1 Lift and move the PUSHER direction switch to the REVERSE position. ;

5.1.4.2 Lift and move the PUSHER direction switch to the FORWARD position. Note the direction of travel of the receiver on the end of the pusher frame. Return the TUG to home end limit switch.

\subsubsection{Skid Installation}

\subsubsection{Skid Common Interface Installation}

5.1.5.1.1 Locate the appropriate Interface plate on the front end of the skid and attach using hardware supplied.

\begin{tabular}{|c|c|c|c|}
\hline SKID & PLATE & BOLT SIZE & \multicolumn{1}{|c|}{ TORQUE } \\
\hline $26 "$ & $8001 \mathrm{~A}-13$ & $1 / 2 "$ & $75 \mathrm{ft}$. Lbs.. \\
\hline $36 "$ & $8001 \mathrm{~A}-14$ & $3 / 4^{\prime \prime}$ & $250 \mathrm{ft}$. Lbs.. \\
\hline $54^{\prime \prime}$ & $8001 \mathrm{~A}-14$ & $3 / 4^{\prime \prime}$ & $250 \mathrm{ft.} \mathrm{Lbs..}$ \\
\hline $63^{\prime \prime}$ & $8001 \mathrm{~A}-14$ & $3 / 4^{\prime \prime}$ & $250 \mathrm{ft}$. Lbs.. \\
\hline $72^{\prime \prime}$ & $8001 \mathrm{~A}-14$ & $3 / 4^{\prime \prime}$ & $250 \mathrm{ft}$. Lbs.. \\
\hline
\end{tabular}


Operation and Maintenance Manual Revision A

\subsubsection{Rigging Guide Installation}

Rigging guides have been supplied for use at the top of the skid when the Strongback is in its vertical position. The guides provide a " $V$ " for the crane operator to more easily place the item in the skid interface. To install the guides, simply bolt the wing pieces onto the rearward side of the hook intercept dish with the captive bolts provided $(2$ bolts per piece). Torque these bolts to approximately $30 \mathrm{ft}$. lbs. Note that a camera is monitoring this area for the operator to further assist the loading phase of the operation. This camera can be adjusted via the manual adjustment feature on the base of the camera. An operator can view the camera adjustment on the monitor to optimize the view of the particular area desired within the camera's view.

\subsubsection{Positioning Skid Lower Guide Wheels}

5.1.5.3.1 After determining the size of the skid to be installed, the Lower Guide Wheels must be set to accommodate the skid. Each set of guide wheels is marked with the different skid size positions.

5.1 5.3.2 Remove the locking pin from the Guide Wheel frame and position the wheel so that the hole in the carrier arm lines up with the appropriate hole in the frame. Install the locking pin in that location.

5.1 5.3.3 Adjust the remaining Guide Wheel sets in the same manner.

\subsubsection{Lifting and Handling of Skid}

The lifting of all skids is accomplished by using a "basket" sling. Slings should be sized according to the weights dictated in section 2.2.3.2 and then using a minimum safety factor of 3 . The slings are to be located at the nominal $1 / 4$ points of the skid length. Care must be taken not to locate a sling where there are base wheels or 45 degree support wheels on the Strongback. The skid is to be lowered gently down onto the Strongback wheels, making sure that the tops of the pipes on either side of the Strongback stay level. This will reduce the need to "clock" the skid after releasing the lift straps. 
Operation and Maintenance Manual Revision A

5.1.5.5 Positioning of Skid in Strongback

The skid shall be lowered such that there is about a $3 \mathrm{ft}$. gap between the front of the skid ( $1 / 2$ " thick plate) and the Strongback front bulkhead (1-1/2" thick platel. Once the skid is on the base wheels, the tug final-push screw jack is used to travel out the nominal $3 \mathrm{ft}$. and retrieve the skid via the ball/hitch and pull it forward to the screw jack engagement location.

5.1 5.5.1 Remove any lifting equipment from the skid.

5.1.5.5.2 Connect trailer to a source of AC power, either on-board generator or local power source. Follow steps 5.1.1 through 5.1 .5 as applicable to enable the control system.

5.1 5.5.3 Make sure that the SKID/STRONGBACK LATCH is in its open position. Use the PUSH function to extend the pusher to its fully extended position. Adjust the position of the ball hitch receiver to mate with the hitch ball attached to the front of the skid.

5.1 5.5.4 Lock the receiver to the ball with the pin provided.

5.1.5.5.5 Use the PUSH function to draw the skid toward the nose of the trailer. Observe the position of the latching ears on the Common Interface Plate. As the skid approaches the top plate of the Strongback the latching ears must . be positioned to pass through the gap in the plate. If they are not positioned correctly, damage to the ball hitch is probable.

5.1.5.5.6 If the skid is rotated on the rollers and is not approaching the gap area properly, it may be necessary to "clock" the skid. See step 5.1.5.7.

5.1 5.5.7 Once the latching ears of the common interface plate are through the gap care must be taken not to continue to draw the skid forward. Again, damage to the ball hitch or ball will occur.

\section{1 .5 .5 .8}

5.1 5.5.9 Observe that both of the latch pins are fully seated in the common interface plate. Close the cover and lock the SKID/STRONGBACK LATCH switch. 
Operation and Maintenance Manual

Revision A

5.1.5.5.10 Unlock and disconnect the ball hitch from the Common Interface Plate ball. If the ball hitch is difficult to remove from the ball, the final push screw jack can be used to move the hitch fore or aft while vertical pressure is applied to pop the hitch up off of the ball. Then, use the holding chain to keep the hitch up out of the way of the rigging guides.

5.1 5.5.11 Using the PUSH function of the tug, retract the arm to its full rear position.

\subsubsection{Strongback Guide Wheel Positioning}

The Strongback is equipped with guide wheels which serve two purposes. First, they keep the skid from oscillating in the wind when the Strongback is in its vertical mode. Second, they resist the rotation of the skid as it is being pushed into the burial container. The wheel sets are located at four locations, two on each side of the trailer. There are five different sets of wheels per location to mate with the skid size being used. Note that the wheels have a "stowed" and "deployed" position. To deploy the wheel sets for the skid being used, follow these steps:

5. 1.5.6.1 Determine what skid diameter is installed.

5.1.5.6.2 Unbolt the vertical leg of the "L" shaped wheel assembly with the appropriate number marking (ie: $26,36,54,63$, or 72 ) from its mounting angles.

5.1.5.6.3 Turn the assembly $90^{\circ}$ so that it's facing the middle of the Strongback and rebolt it loosely to its vertical angle mounts.

5.1.5.6.4 Loosen the 2 bolts on the horizontal arm to allow the wheel to be pushed up against the skid pipe snugly. Vertical adjustment may also be necessary to get both guide wheels to contact the pipe.

5.1.5.6.5 Once both wheels are touching the pipe, tighten both the horizontal arm bolts and the vertical angle bolts. Torque the vertical arm bolts $(1 / 2-13)$ to approximately $40 \mathrm{ft}$. Ibs. Torque the horizontal arm bolts $(3 / 8-16)$ to approximately $16 \mathrm{ft}$. Ibs.

5.1.5.6.6 Repeat these steps for each of the 4 wheel set locations. 
Operation and Maintenance Manual

Revision A

\section{NOTE}

In the event that the skid is pushed into the container and must be pulled back out, it is important that all wheels be returned to their stowed positions.

\subsubsection{Skid Alignment Fixture}

To "clock" the skid due to rotation from loading or from traveling on the wheels, a $4 \times 4$ aluminum tube and a $C$-clamp have been provided. To straighten a skid, span the tube across the top of the $10 \times 3$ top Strongback tubes. Open the clamp enough to reach under the tube on the side that needs to be pulled up and the top of the $4 \times 4$ tube. Tighten the clamp until the tops of the pipes on either side of the skid are at the same height. Measure to the bottom of the $4 \times 4$ tube for reference. Note that the skid must be completely empty when attempting to clock or rotate the skid. Clocking the skid with a load on board may severely damage the skid or the guide wheels.

\subsubsection{Skid Plug Installation}

A plug is installed in the front of each skid to allow water to drain out after being stored outdoors. Note that a red streamer is attached to each plug to draw attention to this area. The plug must be reinstalled before the item is put into the skid to maintain water-tight containment for the item.

\subsubsection{Recheck Plug Installation}

A plug is installed in the front of each skid to allow water to drain out after being stored outdoors. Note that a red streamer is attached to each plug to draw attention to this area. The plug must be reinstalled before the item is put into the skid to maintain water-tight containment for the item.

\subsubsection{Coupling Tractor to Receiver Trailer}

NOTE: The tractor must have an air braking system, 7 pin 12 VDC electrical system and be capable of pulling $145,000 \mathrm{lbs}$ of weight.

5.1.6.1 Maneuver tractor to align with kingpin. Do not couple. 
Operation and Maintenance Manual Revision A

5.1.6.2 When coupling, the tractor brake lines should be connected to the trailer prior to the actual coupling, and the trailer brakes applied.

5.1.6.3 Raise or lower the front landing jacks to match the trailer kingpin height to the tractor fifth wheel height.

5.1.6.4 Back tractor to the trailer and make coupling with trailer kingpin.

5.1.6.5 Connect the tractor's electrical line to the trailer.

5.1.6.6 Check and inspect the trailer connections and fifth wheel operating handles to make certain the two units are properly coupled and that the fifth wheel is securely locked.

NOTE: To make sure that the fifth wheel is fully engaged and locked, apply trailer brakes and rock the tractor forward and backward.

5.1,6.7 Raise the landing jacks.

5.1.6.8 Check brakes, lights and general overall appearance of trailer for proper operation.

\subsubsection{RV Video System}

5.1.7.1 Situate the RV Monitor in the cab of the tractor that is to be used with the Receiver trailer. The monitor power is connected via a Cigarette Lighter plug to a source in the tractor cab.

5.1.7.2 Connect the video/control cable between the monitor and $\mathrm{J} 7$ of the trailer. $J 7$ is located at the nose of the trailer on the Roadside.

5.1.7.3 Set the Monitor power switch to its $O N$ position. The weather cover of the camera will swing open. Within a few seconds, video will appear on the monitor screen.

5.1.8 Verify POWER SOURCE SELECTOR switch, TSRW1, is in the GENERATOR (2) position. 
Operation and Maintenance Manual Revision A

\subsubsection{Hydraulics Start-up}

Make sure that the reservoir is clean and filled with proper hydraulic fluid. Then follow the startup procedure outlined in the Eagle Equipment literature attached.

The hydraulic oil used on these trailers is a UNOCAL product. The part number is UNAX AW \# 46. See Unax Product sheet in the Eagle Equipment Appendix $F$ for more information.

\subsubsection{IR Remote Control Startup}

The IR (InfraRed) control provides a means of controlling the functions of the trailer at a distance of approximately 150 feet from the trailer. The transmission of the IR beam is strictly line-of-sight, therefore location and direction of the transmitter is important. There are $5 \mathbb{R}$ receivers located on the trailer, two each on the roadside and curbside and one at the rear of the trailer.

The IR control parallels the functions of the Pendant control.

5.1.10.1 In the IR Control box, set the RADIO/PENDANT switch to the RADIO position.

5.1.10.2 On the IR Transmitter box, Insert the key that is attached to the carrying handle into the key switch marked POWER. Turn key fully clockwise.

5.1.10.3 Press the Press-To-Test BATTERY TEST light located next to the switch. The lamp should illuminate.

5.1.10.4 Press the green START button on the transmitter.

5.1.10.5 The upper Green LED on the Processor Card will illuminate. Each time a control on the IR Transmitter is activated, the second Green LED on the Processor Card will flash. A Red LED on the Transmitter array will also flash indicating that a data stream is being transmitted.

5.1.10.6 On the front panel of the right hand control box, press the green CONTROL ENABLE button. The Green POWER ON lamp will light.

\section{9}


Operation and Maintenance Manual Revision A

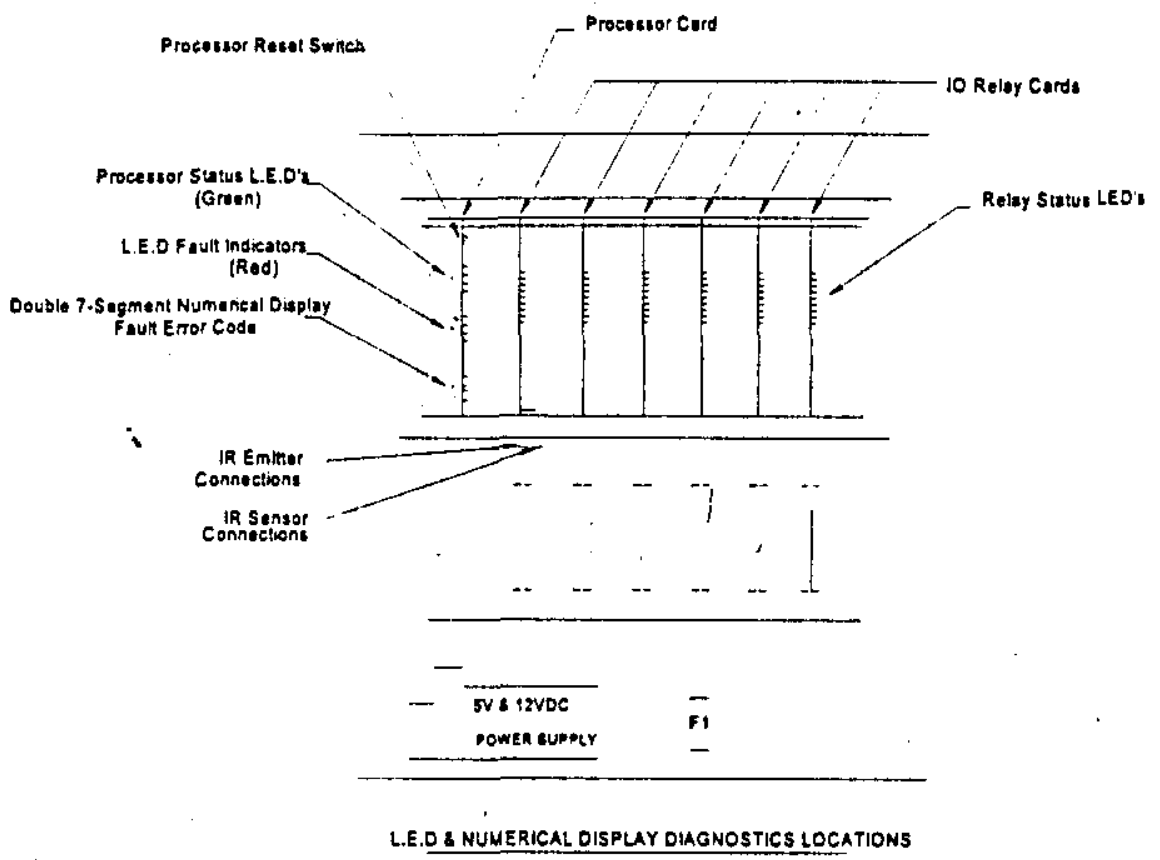

\subsubsection{IR Remote Control Function Checkout}

\subsection{Undercarriage - Lock / Release}

5.1.10.7.1.1 With the hydraulic system running, lift and move the LOCK/RELEASE switch to the LOCK position. Observe that the undercarriage locking cylinder extends.

5.1.10.7.1.2 Release the LOCK/RELEASE switch. Movement of the locking cylinder will stop.

5.1.10.7.1.3 Lift and move the LOCK/RELEASE switch to the RELEASE position. Observe that the undercarriage locking cylinder retracts. Release the LOCK/RELEASE switch.

\subsection{Level - Up / Down \& Jack Select}

5.1.10.7.2.1 Move the JACK SELECT switch to the RF position (Right or Curbside Front). Press the JACK SELECT ENABLE button. 
Operation and Maintenance Manual Revision A

5.1.10.7.2.2 Lift and move the LEVEL switch toward the DOWN position. The jack at the curbside front of the trailer will move up toward its transport location.

5.1.10.7.2.3 Repeat steps 5.1.7.2.1 through 5.1.7.2.2 for the LF (Roadside Front), RR (Curbside Rear), LR (Roadside Rear) and ALL positions. The JACK SELECT ENABLE button must be pressed each time the JACK SELECT switch position is changed.

5.1.10.7.3 Slide - Left / Right \& Slide Select

5.1.10.7.3.1 Check that both Front and Rear cross slide tubes are in their centered position.

\section{NOTE}

Leveling/lifting jacks must be in such a position as to have the wheels of the undercarriage off the ground during this test sequence.

5.1.10.7.3.2 Set SLIDE SELECT switch to the FRONT position. Press the SLIDE SELECT ENABLE button.

5.1.10.7.3.3 Lift and move the SLIDE switch to the LEFT position. The FRONT cross slide motor will operate.

5.1.10.7.3.4 Set SLIDE SELECT switch to the REAR position. Press the SLIDE SELECT ENABLE button.

5.1.10.7.3.5 Lift and move the SLIDE switch to the RIGHT position. The REAR cross slide motor will operate.

5.1.10.7.3.6 Using the SLIDE controls, return the trailer to its centered position.

5.1 10.7.3.7 Set SLIDE SELECT switch to the ALL position. Press SLIDESELECT ENABLE button.

5.1 10.7.3.8 Lift and move the SLIDE switch to the RIGHT position. Both the FRONT and REAR cross slide motors will operate. 
Operation and Maintenance Manual

Revision A

5.1.10.7.3.9 Lift and move the SLIDE switch to the LEFT position. Both the FRONT and REAR cross slide motors will operate. Return the trailer to its centered position.

5.1.10.7.6 Strongback Motion \& Strongback Direction - Up / Down

5.1 10.7.6.1 All four leveling jacks must be down and the trailer brought into a level condition. See step 5.1.5.7 for leveling instructions. The TUG must be in its parked position.

Note: IF NEITHER SHORE SOURCE IS AVAILABLE, THE ONBOARD GENERATOR MAY BE USED FOR SETUP. HOWEVER, THE OUTRIGGER AND LEVELING JACKS MUST BE OPERATED ONE AT A TIME.

5.1 10.7.6.2 Start the Hydraulic Power Supply by pressing the HYDRAULIC PUMP START switch (SW15). Both DS4 (HYDRAULIC PUMP \# 1 RUNNING) and DS5 (HYDRAULIC PUMP \#2 RUNNING) on the control box shall illuminate.

5.1.10.7.6.3 Lift and move the STRONGBACK DIRECTION switch to the RAISE position. Hold STRONGBACK DIRECTION switch in this position until the top end of the Strongback has lifted approximately 24 " above the forward Vee blocks. Release STRONGBACK DIRECTION switch. See step 5.1.5.8 for angular position indication.

5.1 10.7.6.4 Lift and move the STRONGBACK DIRECTION switch to the LOWER position. Hold STRONGBACK DIRECTION switch in this position until the top end of the Strongback has returned to its full down position. DS11 (STRONGBACK DOWN) shall illuminate. Release STRONGBACK DIRECTION switch.

5.1.10.7.7 E-Stop

5.1 10.7.7.1 Press the red E-STOP button on the IR transmitter. KEPO will drop out and stop all control action.

NOTE

The E-STOP switch does NOT disconnect AC power from the Control Box. 
Operation and Maintenance Manual Revision A

5.1.10.7.7.2 Press the CONTROL ENABLE switch to restore control.

5. 1.10.7.8 Steering Right / Left

Note that the Strongback must be in the down position and the jacks must be in the up position to allow the steering to operate correctly.

The Steering controls are located only on the IR Transmitter. The intended function of this system is to enable personnel in a chase vehicle to steer the rear end of the trailer around tight corners.

For normal transit the undercarriage must be restrained in a centered condition. At the forward end of the front undercarriage assembly is a lunette eye that is extended to mate with the hook mounted to the frame. The locking bar must be connected to the hook during transit.

During operations where an LLCE is being handled, the locking bar must be in the fully retracted position. There is a locking pin that also must be inserted in the locking bar to retain it in its retracted position. An additional interlock is provided by a switch that senses the position of the bar. This switch must be actuated before the steering system will operate.

\subsection{Start Generator per section 5.1.2.}

Open the door on the left hand control cabinet.

5.1.10.7.8.2 Set Power Source select switch (TRSW1) to position 2 (Generator).

5.1.10.7.8.3 Set the generator Circuit Breaker, CB2, to its ON position.

5.1.10.7.8.4 Set the Main Circuit Breaker, CB1, to its ON position. If CB1 has been tripped by the Shunt Trip circuit, the breaker handle will have to be moved to OFF position, then to ON position. This will reset the Shunt Trip.

5.1.10.7.8.5 Set MSP1 to its ON position.

5.1.10.7.8.6 Set MSP2 to its OFF position. The generator is not able to operate both hydraulic pumps at the same time. Either pump \#1 or \#2 may be operated for this function (interchange references to MSP1 \& MSP2). 
5.1.10.7.8.7 Set CB3 and CB4 to their ON positions.

Open the door of the right hand control box.

5.1.10.7.8.8 Set $C B 7$ and $C B 8$ to their $O N$ positions.

Open the door of the IR control Cabinet.

5.1.10.7.8.9 Set the RADIO/PEND. Switch to the RADIO position.

Locate the IR Control Transmitter for the Receiver Trailer.

5.1 1 10.7 .8 .10 Insert the key that is attached to the carrying handle into the key switch marked POWER. Turn key fully clockwise.

5.1 10.7.8.11 Press the Press-To-Test BATTERY TEST light located next to the switch. The lamp should illuminate.

5.1.10.7.8.12 Press the green START button on the transmitter.

5.1.10.7.8.13 Release the pintle hook latch on the undercarriage and move the lunette eye to its stowed position.

5.1.10.7.8.14 On the curbside of the Receiver Trailer undercarriage, set the hydraulic equalization valve to its OFF position.

5.1.10.7.8.15 On the front door of the lefthand control box, press the CONTROL ENABLE button. The green POWER ON light should illuminate.

5.1.10.7.8.16 On the front of the lefthand control box, press the HYDRAULIC PUMP START button. Hydraulic pump \#1 should start. If MSP2 is selected in step 5.1.7.8.5, pump \#2 will start.

5.1.10.7.8.17 On the IR transmitter, briefly place the STEERING switch in the LEFT position, the front undercarriage assembly should move slightly toward the left. To move the switch from its center position, it is necessary to lift up on the switch before moving it toward the left or right. 
Page missing from vendor $\mathrm{O}$ and $\mathrm{M}$ manual 
Operation and Maintenance Manual Revision A

\begin{tabular}{|c|l|c|}
\hline ITEM & DESCRIPTION & CHECK-OFF \\
\hline 1 & 5.1 .1 Power Source Selected & \\
\hline 2 & 5.1 .2 .1 Generator Started & \\
\hline 3 & 5.1 .2 .2 Power Checked & \\
\hline 4 & 5.1 .3 Tug Direction Selected / Confirmed & \\
\hline 5 & 5.1 .4 Tug Pusher Direction Forward & \\
\hline 6 & 5.1 .5 .1 Skid Removable Interface Installed & \\
\hline 7 & 5.1 .5 .2 Rigging Guides Installed & \\
\hline 8 & $\begin{array}{l}5.5 .5 .3 \text { Skid Lower Guide Wheels } \\
\text { Positioned }\end{array}$ & \\
\hline 9 & 5.1 .5 .4 Skid Lifting Straps Ready & \\
\hline 10 & $\begin{array}{l}5.1 .5 .5 \text { Skid Installed into Strongback } \\
\text { Interface Tabs }\end{array}$ & \\
\hline 11 & $\begin{array}{l}5.1 .5 .5 .8 \text { Latch Pins Installed in Skid } \\
\text { 5.1.5.8 Plug Check on Front of Skid }\end{array}$ & \\
\hline 12 & &
\end{tabular}

5.2 Transport Trailer Setup (TL8002-01) (After Long Term Storage > 3 Months)

The Electrical system of the Transport Trailer (TL8002-01) is designed to operate on the $480 \mathrm{~V}$ Delta connected power available on the Hanford site.

\subsubsection{Power Source Selection}

Located inside the lefthand control box is the power source selector switch, TRSW1. Position 1 selects input from an external source, the center position is a neutral or OFF position and position 2 selects the On-Board generator as the power source.

\subsubsection{Generator Operation}


Operation and Maintenance Manual Revision A

\subsubsection{Starting}

The generator may be started from either of two locations. The first is a control box located on the right front of the engine. It contains an ON/OFF switch, a Glow PJug heat switch, a Glow Plug indicator, an hour meter and an engine start button. The second is remotely located near the electrical control boxes on the roadside of the trailer.

The starting sequence using the engine mounted controls is:

1. Set the toggle switch located at the top of the panel to the $O N$ position.

2. If the ambient temperature is below $40^{\circ} \mathrm{F}$, press and hold the Glow Plug button. Observe the glow plug located on the panel, when it begins to glow red, release the button. If the temperature is above $40^{\circ} \mathrm{F}$ it is usually not necessary to preheat the glow plugs.

3. Press the Start button. The engine should start after a brief period of cranking. If the engine does not start immediately, release the Start button, wait 30 seconds and try again.

4. If the engine will not start, see the manufacturer's manual for further instructions.

The starting sequence using the remote mounted controls is:

1. Insert the key into the ignition switch.

2. If the ambient temperature is below $40^{\circ} \mathrm{F}$, turn the key CCW and hold for no longer than 15 seconds. If the temperature is above $40^{\circ} \mathrm{F}$ it is usually not necessary to preheat the glow plugs.

3. Turn the key fully $\mathrm{CW}$ to the Start position, hold in this position until the engine starts but no longer than 10 seconds in the event that the engine does not start.

4. When engine starts, release the key, it will move to the RUN position. 
Operation and Maintenance Manual

Revision A

5. If the engine does not start, see the manufacturer's manual for instructions.

\subsubsection{Generator Power Check}

5.2.2.2.1 Set POWER SOURCE SELECTOR switch, TSRW1, to the GENERATOR (2) position.

5.2.2.2.2 In Control Box 1, set $C B 2$ to its ON position.

5.2.2.2.3 In Control Box 1, set CB1 to its ON position.

5.2.2.2.4 Observe the LEDs located on the power monitor, neither should be illuminated. CB1 should remain in its ON position.

\subsubsection{Laser Alignment System Installation and Calibration}

Before the laser alignment system can be used, there must be confirmation that the laser is set up parallel to the burial container. This can be accomplished by the following steps:

5.2.3.1 Install the LASER on its mounting pedestal near the nose of the trailer. Hand tighten the mounting bolts that mount the laser to the base.

\section{NOTE}

Check and/or replace the batteries, 4 Alkaline "D" Cells, each month.

\subsubsection{Set the MAN/OFF/AUTO switch to the MAN position.}

5.2.3.3 The laser has the capability to adjust the rotation speed via. a small black knob located to the right of the MAN/OFF/AUTO switch. Rotation may be either Clockwise (CW) or Counter-Clockwise (CCW) or stationary. The knob has a center decent position which will stop the beam rotation.

\subsubsection{Using your hand, locate the beam direction. Now turn the knob very} slightly until the beam "creeps" toward the red line located on the trailer deck near the roadside trailer ladder access area. Stop the beam when it is within the length of the red line. 
Operation and Maintenance Manual Revision A

5.2.3.5 Calibrate the laser, if necessary, by turning the knob on the LASER that is closest to the front of the transport trailer. Turning this knob will move the beam left and right on the deck. Do not turn the knob that faces the rear of the trailer. This knob was preset at MSt.

5.2.3.6 Once the laser beam is hitting this line within $\pm 1 / 8 "$, the LASER is considered calibrated to the deck and the burial container.

\subsubsection{Install Burial Container Chocks}

Full length chocks have been provided for each of the five burial container diameters. Note that the chocks are split into $52 \mathrm{ft}$. and $18 \mathrm{ft}$. sections. For $52 \mathrm{ft}$. burial containers, the $52 \mathrm{ft}$. chock is used by itself. For a $70 \mathrm{ft}$. burial container, the $18 \mathrm{ft}$. section is added on. The chocks are anchored to the trailer deck via ISO type twist locks. Note that the anchor points are not symmetrical along the length of the chock, primarily to insure that the chock is installed properly to work with the burial container straps. The chocks are "basket" lifted similar to the skids. Locate the basket slings at the nominal $1 / 4$ points of the length of the chock. A single crane may lift the chocks as long as the pick height is approximately $25 \mathrm{ft}$. above the chock. This will reduce the horizontal loads induced in the chock assembly. Once the chock is set over the twist locks on the deck, go below the deck and turn the twistlock handles 90 degrees to lock the castings down. If the additional 18 $\mathrm{ft}$. section is to be used ( $70 \mathrm{ft}$. container), this section should be put in first.

\subsubsection{Lifting Beam Rigging for Burial Container}

The lifting beam, as provided by SEG, is equipped with rigging for both lifting the beam with the crane, and therefore lifting the container with the beam. The straps are strategically placed in order to miss the straps that anchor the burial container to the full length chock. The SEG lifting procedure should be followed when rigging or lifting a container.

\subsubsection{Position Beam in Supports}

As the container is lowered into the chock and the straps fall to rest on the container, the lifting beam can be installed in the supports provided on the curbside deck. There are two beam sizes supplied by SEG, one at $52 \mathrm{ft}$. and one at $72 \mathrm{ft}$. in length. The rear beam support is used for both beam sizes. The middle support, combined with the rear support, houses the shorter 
Operation and Maintenance Manual

Revision A

beam. All supports are used for the long beam. As the beam is lowered into the supports, care must be taken to not damage the rigging points along the bottom of the beam. Once the beam is lowered into the base of the support, there is no need to lash the beam down as the shear weight of the beam keeps it trapped in the transit mode. Rubber matting is installed in the bottom of each support to protect the paint finish on the beam. The rigging attached to the top of the beam can be draped over the side of the trailer for the transit mode.

\subsubsection{Install Hydraulic Cylinders on Chocks}

Depending on which Burial Container/Chock combination is installed, either eight (8) or ten (10) Latch Cylinders will be installed.

5.2.7.1 Locate the required number of Latch Cylinder Assemblies. Note that there are three (3) Left hand assemblies and seven (7) Right hand assemblies.

5.2.7.2 Position the Latch Cylinder Assemblies at each pad location on the chock. Attach each assembly with the 3/4-10 Grade 8 bolts and hardware provided. Torque these bolts to nominal $150 \mathrm{ft}-\mathrm{lbs}$.

5.2.7.3 Thread the hydraulic hose/cable through the holes in the deck and connect them the hydraulic and cable connectors below the deck. Join the two cable caps.

\section{NOTE}

For the Chocks that use only eight $(8)$ assemblies, electrical dummy plugs must be inserted into the two (2) unused connectors.

\subsubsection{Tie-down/Tarp Installation}

Each burial container is equipped with a white tarp to lessen the thermal effects on the burial container (expansion/contraction). The tarp is integrated with the straps to keep the proper length strap with its tarp, and the tarp is in two pieces to match with the $52 \mathrm{ft}$. and $18 \mathrm{ft}$. chock sections. The straps are fed under the tarp for aesthetics. 
Operation and Maintenance Manual Revision A

To install a tarp assembly, follow these steps:

1. Put the tarp on top of the burial container in its folded configuration.

2. Unwrap the tarp approximately $15 \mathrm{ft}$. and evaluate if the tarp is oriented end-to-end properly with the burial container.

3. Once it is confirmed that the tarp is oriented properly, fully unroll the tarp and straps. If the straps are not installed in the tarp, follow the below chart to match the tarp with its straps.

\begin{tabular}{|c|c|c|}
\hline $\begin{array}{c}\text { Container } \\
\text { Size } \\
\text { (diameter) }\end{array}$ & Tarp Width & Strap length (overall) \\
\hline 26 & 32 & 56 \\
\hline 36 & 45 & 75 \\
\hline 54 & 70 & 104.375 \\
\hline 63 & 91.5 & 124.5 \\
\hline 72 & 91.5 & 141 \\
\hline
\end{tabular}

4. The ends of each strap are distinctly different. One end is simply a terminated strap (4" wide). The other end has a loop built into the strap to accept a chain shackle. If the shackle is not on the loop end, unscrew the pin from the shackle, feed the shackle through the strap, and attach the common pin block to the shackle. The pin block has two holes in it, one for pinning to the shackle, the other for mating with the hydraulic unit. After pinning the block to the shackle, center the pinning block hole with the hydraulic unit pin so that as hydraulic pressure is released, the spring pin with throw the pin through this pin block hole. Keep all pin blocks centered as closely as possible before releasing hydraulic pressure. 
Operation and Maintenance Manual

Revision A

5. Once the pins are thrown through the pin block holes (some individual pin "coaxing" may be required), install the rachet lever arm in the first rachet on the opposite side of the container. Feed the 4" strap through the rachet slot and rotate the rachet with your hand as tightly as possible while holding the rachet tooth stop in place. Using the lever arm supplied, rotate the rachet (tighten the strap) until the strap is snug on the burial container. Do not over tighten the straps as this may damage the burial container. Repeat these steps for each strap location.

\subsubsection{Checklist to Complete Long Term Storage Checkout}

\begin{tabular}{|c|c|c|}
\hline Item & Description & Check-Off \\
\hline 1 & Outrigger feet stowed & \\
\hline 2 & Tiedowns in place & \\
\hline 3 & Access ladder stored & \\
\hline 4 & Storage box doors closed and secured & \\
\hline 5 & All chock twistlocks turned to the locked position & \\
\hline 6 & $\begin{array}{l}\text { The laser is secured to the laser station (or removed } \\
\text { completely) }\end{array}$ & \\
\hline 7 & $\begin{array}{l}\text { All handrails are installed and secured with the thumb } \\
\text { screws }\end{array}$ & \\
\hline 8 & The front end restraint wall is secured to the trailer floor & \\
\hline 9 & The side shield walls are pinned to the trailer frame & \\
\hline 10 & The power cable is secured to its reel & \\
\hline 11 & All burial container straps are secured over the container & \\
\hline 12 & $\begin{array}{l}\text { The air lines have been properly connected from the } \\
\text { tractor to the trailer }\end{array}$ & \\
\hline 13 & $\begin{array}{l}\text { The safety chain between the front axle and the frame } \\
\text { below the trailer deck has been removed and put in the } \\
\text { storage box }\end{array}$ & \\
\hline
\end{tabular}


Operation and Maintenance Manual Revision A

5.2.10 Coupling Tractor to Trailer (Ready to be Deployed)

NOTE: The tractor must have an air braking system, 7 pin 12 VDC electrical system.

5.2.10.1 Maneuver tractor to align with kingpin. Do not couple.

5.2.10.2 When coupling, the tractor brake lines should be connected to the trailer prior to the actual coupling, and the trailer brakes applied.

5.2.10.3 Raise or lower the front landing jacks to match the trailer kingpin height to the tractor fifth wheel height.

5.2.10.4 Back tractor to the trailer and make coupling with trailer kingpin.

5.2.10.5 Connect the tractor's electrical line to the trailer.

5.2.10.6 Check and inspect the trailer connections and fifth wheel operating handles to make certain the two units are properly coupled and that the fifth wheel is securely locked.

NOTE: To make sure that the fifth wheel is fully engaged and locked, apply trailer brakes and rock the tractor forward and backward.

5.2.10.7 Raise the landing jacks.

5.2.10.8 Check brakes, lights and general overall appearance of trailer for proper operation.

\subsection{Cold Trailer Alignment}

Move the Receiver and Transport Trailers to the specified arrangement or location identified by the general arrangement drawing. Disregard this section if trailers are essentially positioned back to back with the tank farm.

5.3.1 Park transport trailer in approximate final location. Note that the pads on the bottom of the outriggers are sized for a maximum of 60 PSI soil bearing pressure (Worst case on front outriggers).

\subsubsection{Uncoupling the tractor.}


Operation and Maintenance Manual Revision A

5.3.2.1 Lower the two front landing gear jacks. After the landing jacks have contacted the ground, crack a few extra turns to allow some of the trailer weight to be supported by the jacks.

NOTE: When uncoupling the trailer from the tractor, make certain the landing jacks are lowered sufficiently.

5.3.2.2 Disconnect the tractor's electrical line from the trailer.

5.3.2.3 Disconnect both tractor brake lines from the trailer's gladhands.

5.3.2.4 Open the fifth wheel lock, then pull the tractor ahead until the two units are separated.

\subsubsection{Shore Power/ Connection Test}

5.3.3.1 Unstow and connect Shore Power Cable to J2 on Control Box 1 .

\section{NOTE}

The entire 200 foot length of the power cable must be removed from the cable reel. Provision has been made on the shore end of the cable for pulling by a vehicle.

5.3.3.2 Connect Shore Power Cable to source of 480VAC Delta, 3 Phase 3 Wire and Ground.

5.3.3.3 Set Power Source Selector Switch (TRSW1) to the SHORE position (position 1).

5.3.3.4 Set the Shore Power source to its ON position.

5.3.3.5 Set CB1, Located in Control Box 1 to its $O N$ position. CB1 Shall remain in Its $O N$ position.

\section{NOTE}

If $C B 1$ does not remain in its $O N$ position, it is an indication that the input phasing is incorrect. To correct a phasing problem any two of the input phases must be interchanged. A qualified electrician familiar with the site power system should make the correction. 
Operation and Maintenance Manual Revision A

\subsubsection{IF NEITHER SHORE SOURCE IS AVAILABLE, THE ONBOARD GENERATOR} MAY BE USED FOR SETUP. HOWEVER, THE OUTRIGGER AND LEVELING JACKS MUST BE OPERATED ONE AT A TIME.

5.3.4 Lower jack pads until they make ground contact.

5.3.5 Check that the access platform has been prestaged for use after alignment and transfer. Check with safety officer if safety railing and back end chains have been removed if needed.

5.3.6 Using the RV camera on the rear of the trailer and a flagger or other aides, back the Receiver trailer into alignment with the Transport trailer.

Backing of the receiver trailer into the transport trailer requires a straight stretch of roadway so that the steerable bogie can be placed in alignment with the trailer bed. Use of the steering controls for the rear bogie should be avoided and backing adjustments shall be completed by the tractor trailer driver.

The mating of the rear of the trailers is accomplished with the dock bumpers fitting between the vertical tubes on the receiver trailer.

The receiver trailer driver must watch the video camera provided in order to center the trailers with each other as closely as possible when backing. The dock bumper must be within these vertical tubes.

After achieving the mating of the two trailers mark the wheel base and outrigger locations and project those line up to 80 feet for alignment aid.

Decouple the trailers and move the receiver trailer to its location within the tank farm.

\subsection{Receiver Trailer Tank Farm Checkout/Setup}

5.4.1 Park Receiver trailer in its approximate final location for loading LLCE

\subsubsection{Uncouple tractor}


Operation and Maintenance Manual Revision A

5.4.2.1 Lower the two front landing gear jacks. After the landing jacks have contacted the ground, crack a few extra turns to allow some of the trailer weight to be supported by the jacks.

NOTE: When uncoupling the trailer from the tractor, make certain the landing jacks are lowered sufficiently.

5.4.2.2 Disconnect the tractor's electrical line from the trailer.

5.4.2.3 Disconnect both tractor brake lines from the trailer's gladhands.

5.4.2.4 Open the fifth wheel lock, then pull the tractor ahead until the two units are separated.

5.4.2.5 Move the tractor at least 10 feet from the trailer to allow access to the front end for radiation monitoring.

5.4.3 Shore Power Connection/Test

5.4.3.1 Unstow and connect Shore Power Cable to J2 on Control Box 1.

NOTE

The entire 200 foot length of the power cable must be removed from the cable reel. Provision has been made on the shore end of the cable for pulling by a vehicle.

5.4.3.2 Connect Shore Power Cable to source of 480VAC Delta, 3 Phase 3 Wire and Ground.

5.4.3.3 Set Power Source Selector Switch (TRSW1) to the SHORE position (position 1).

5.4.3.4 Set the Shore Power source to its ON position.

5.4.3.5 Set CB1, Located in Control Box 1 to its $O N$ position. CB1 Shall remain in Its $\mathrm{ON}$ position. 
Operation and Maintenance Manual Revision A

\section{NOTE}

If CB1 does not remain in its ON position, it is an indication that the input phasing is incorrect. To correct a phasing problem any two of the input phases must be interchanged. A qualified electrician familiar with the site power system should make the correction.

5.4.3.6 In Control Box 1, set circuit breakers $\mathrm{CB} 3$ and $\mathrm{CB} 4$ to their $\mathrm{ON}$ positions. CB3 provides Control Power via T1. CB4 provides $120 \mathrm{~V}$ utility power via T2.

5.4.3.7 In Control Box 2 set the Utility Power circuit breakers CB17 through CB20, CB23 and CB24 to their ON positions.

\begin{tabular}{|c|c|c|}
\hline Ref. & Type & Function \\
\hline CB1 & 125 A 3 Pole & MAIN INPUT \\
\hline CB2 & 30 A 3 Pole & GENERATOR \\
\hline CB3 & 15 A 2 Pole & CONTROL POWER TRANSFORMER \\
\hline CB4 & 15 A 2 Pole & UTILITY POWER TRANSFORMER \\
\hline CB5-CB16 & NOT USED & UTILITY MAIN \\
\hline CB17 & 30 A 2 Pole & UTILITY RECEPTACLES \\
\hline CB18 & 15 A 1 Pole & CAMERA LIGHTS \\
\hline CB19 & 15 A 1 Pole & HYDRAULIC SUMP HEATER \\
\hline CB20 & $15 \mathrm{~A} 1$ Pole & NOT USED \\
\hline CB21 & $15 \mathrm{~A} 1$ Pole & CABINET INTERIOR UTILITY \\
\hline CB22 & $15 \mathrm{~A} 1$ Pole & HEAT EXCHANGER \\
\hline CB23 & $15 \mathrm{~A} 1$ Pole & IR CONTROL \\
\hline CB24 & $15 \mathrm{~A} 1$ Pole & DC POWER SUPPLY LASER RECEIVER \\
\hline CB25 & $15 \mathrm{~A} 1$ Pole &
\end{tabular}


Operation and Maintenance Manual

Revision A

5.4.3.8 Press CONTROL POWER ENABLE switch SW2 located on the front door of Control Box 2. POWER ON lamp, PL1, on the pendant control shall illuminate.

\subsubsection{Pendant Control Connection}

5.4.4.1 Unstow and connect the pendant control station to J1 on Control Box 1 .

5.4.4.2 Set CB3, also located in Control Box 1, to its ON position.

POWER ON lamp, DS1 located on the door of Control Box 2 shall illuminate.

\subsubsection{Pendant Control Function Checkout}

Press the CONTROL ENABLE switch (SW2) on the front of Control Box 1. The green POWER ON lamp on the pendant shall illuminate.

\subsubsection{Undercarriage Lock / Release}

This control cycles a hydraulic cylinder that keeps the undercarriage from pivoting while the trailer is being raised. There is an interlock switch on this cylinder that prevents steering motion unless this cylinder is in the full DOWN position. Note that this cylinder must be in the full down position before any road travel is attempted or damage to the cylinder or undercarriage of the trailer may occur.

5.4.5.1.1 With the hydraulic system running, turn the LOCK/RELEASE switch (SW4) to the LOCK position. Observe that the undercarriage locking cylinder extends.

5.4.5.1.2 Release the LOCK/RELEASE switch. Movement of the locking cylinder will stop.

5.4.5.1.3 Turn the LOCK/RELEASE switch (SW4) to the RELEASE position. Observe that the undercarriage locking cylinder retracts. Return the locking cylinder to its full down position. Release the LOCK/RELEASE switch. 
Operation and Maintenance Manual

Revision A

\subsubsection{Level - Up / Down \& Jack Select}

These two switches allow the operator to select which of the jacks to move and what direction to move them. As stated in the definitions, Right refers to motion toward the Curbside, Left is toward the Roadside, Up and Down refer to motion of the trailer not the jacks. Also note that there is a non functional position of the JACK SELECT switch at its full clockwise position. The JACK SELECT switch must be returned to the OFF position for other down stream functions to operate.

5.4.5.2.1 Move the JACK SELECT switch (SW6) to the RF (Right or Curbside Front).

5.4.5.2.2 Turn the LEVEL switch toward the DOWN position. The jack at the curbside front of the trailer will move up toward its transport location and will stop when it trips the Down Limit LS2. Briefly turn the LEVEL switch to the UP position to back the jack off the limit.

5.4.5.2.3 Move the JACK SELECT switch (SW6) to the RF (Right or Curbside Front).

5.4.5.2.4 Turn the LEVEL switch toward the UP position. The jack at the curbside front position on the trailer will begin to move toward the ground (moving the trailer in an upward direction). Hold the switch in the UP position until the footpad of the jack reaches the ground.

5.4.5.2.5 Move the JACK SELECT switch (SW6) sequentially to the LF, RR and LR positions, repeat step 5.1.5.2.4 at each position.

NOTE

See section 5.1.5.7 for leveling indicator checkout.

5.4.5.2.6 Move the JACK SELECT switch (SW6) to the ALL position.

5.4.5.2.7 With the hydraulic system running, turn the LOCK/RELEASE switch (SW4) to the LOCK position. Observe that the undercarriage locking cylinder extends. Continue to hold the switch in the LOCK position until the lock contacts the pad on the trailer frame. 
Operation and Maintenance Manual

Revision A

5.4.5.2.8 Turn the LEVEL switch toward the UP. position. ALL four of the jacks will drive, lifting the trailer. Continue to hold the LEVEL switch in the UP position until the wheels are off the ground.

\section{NOTE}

At this point, proceed to step 5.1.5.3 to perform the Slide checks, then return to this step.

5.4.5.2.9 Turn the LEVEL switch to the DOWN position. Lower the trailer back to the ground, continue to hold the LEVEL switch in the DOWN position until the jacks are raised into their transport configuration.

5.4.5.2.10 Turn the LOCK/RELEASE switch (SW4) to the RELEASE position. Hold the switch in this position until the locking cylinder is fully retracted.

5.4.5.3 Slide - Left / Right \& Slide Select

The SLIDE function of the Receiver trailer allows independent motion of the Front and Rear cross slides. It will also permit both front and rear slides to be moved in the same direction at the same time.

The slide function is limited to movement of \pm 3 inches from a centered position. The centered position is indicated by a color band on the cross slides.

5.4.5.3.1 Check that both Front and Rear cross slide tubes are in their centered position.

NOTE

Leveling/lifting jacks must be in such a position as to have the wheels of the undercarriage off the ground during this test sequence.

5.4.5.3.2 Set SLIDE SELECT switch (SW7) to the FRONT position.

5.4.5.3.3 Turn the SLIDE switch (SW8) to the LEFT position. The FRONT cross slide motor will operate as long as SW8 is held in position and until the slide direction limit is reached. 
Operation and Maintenance Manual Revision A

5.4.5.3.4 Turn the SLIDE switch (SW8) to the RIGHT position. The FRONT cross slide motor will operate as long as SW8 is held in position or until the slide direction limit is reached.

5.4.5.3.5 Set SLIDE SELECT switch (SW7) to the REAR position.

5.4.5.3.6 Turn the SLIDE switch (SW8) to the LEFT position. The REAR cross slide motor will operate as long as SW8 is held in position or until the slide direction limit is reached.

5.4.5.3.7 Turn the SLIDE switch (SW8) to the RIGHT position. The REAR cross slide motor will operate as long as SW8 is held in position or until the slide direction limit is reached.

5.4.5.3.8 Set SLIDE SELECT switch (SW7) to the ALL position.

5.4.5.3.9 Turn the SLIDE switch (SW8) to the LEFT position. Both the FRONT and REAR cross slide motors will operate as long as SW 8 is held in position or until the slide direction limit is reached.

\subsubsection{Tug Direction - Forward / Reverse}

In order for the TUG to move several conditions must be met. The Strongback must be in its full DOWN position, the Pusher Power (P5) and Limit switch (P3) connectors must be disconnected and JACK SELECT switch (SW6) must be in its OFF position.

\section{NOTE}

For the purposes of this functional test the skid must not be in place on the Strongback.

5.4.5.4.1 Turn the TUG DIRECTION switch (SW9) to the FORWARD position. The tug shall move to its full forward position (nose of the trailer), the TUG PARKED light (DS6) on the control box will illuminate.

5.4.5.4.2 Insert P5 into J5 (Pusher Power) and P3 into J3 (Pusher Limit Switches).

5.4.5.4.3 Turn the TUG DIRECTION switch (SW9) to the REVERSE position. The tug shall not move. 
Operation and Maintenance Manual Revision A

5.4.5.4.4 Disconnect P5 from J5 (Pusher Power) and P3 from J3 (Pusher Limit Switches).

5.4.5.4.5 Turn the TUG DIRECTION switch (SW9) to the REVERSE position. The tug shall move to its full AFT position (rear of the trailer), the TUG PARKED light (DS6) on the control box will extinguish as soon as the tug begins to move.

When the tug reaches its full aft position, the TUG AFT LIMIT light on the control box will illuminate. The winch drive motor will stop.

5.4.5.4.6 Return the Tug to its PARKED position at the nose of the trailer.

5.4.5.5 Pusher - Forward / Release

The PUSHER motor on the tug is supplied with power only at the extreme forward and aft limits of travel of the tug. Limit switches LS12 and LS13 are mounted on the Pusher frame and must be connected via P3 and either $\mathrm{J} 3$ at the forward end of the trailer or $\mathrm{J} 4$ at the aft end of the trailer.

5.4.5.5.1 Set the PUSHER direction switch (SW10) to the REVERSE position. Hold the switch in this position until the PUSHER assembly reaches its fully retracted position.

5.4.5.5.2 Set the PUSHER direction switch (SW10) to the FORWARD position. Hold the switch in this position until the PUSHER assembly reaches its fully extended position.

5.4.5.6 Strongback Motion \& Strongback Direction - Up / Down

NOTE

For the purposes of this test, the Strongback will be raised no more than 24 " from its horizontal position.

5.4.5.6.1 All four leveling jacks must be down and the trailer brought into a level condition. See step 5.1.5.7 for leveling instructions. The TUG must be in its parked position. 
Operation and Maintenance Manual

Revision A

Note:

In order to not risk damaging the equipment due to low temperatures, it is necessary to heat the hydraulic oil prior to use. The system does have a heater for this purpose, however it does take a fair amount of time to arrive at the proper temperature. The recommended operating temperature for the oil is approximately 90 deg.F. A thermometer is built into the system for monitoring. If time is of the essence, both hydraulic pumps can be used to also heat the oil, provided the oil temperature is $\mathbf{5 0}$ degrees $F$ or above.

5.4.5.6.2 Start the Hydraulic Power Supply by pressing the HYDRAULIC PUMP START switch (SW 15). Both DS4 (HYDRAULIC PUMP \# 1 RUNNING) and DS5 (HYDRAULIC PUMP \#2 RUNNING) on the control box shall illuminate.

5.4.5.6.3 Set the STRONGBACK DIRECTION switch (SW12) to the RAISE position.

5.4.5.6.4 Press the STRONGBACK MOTION switch (SW11). Hold SW11 depressed until the top end of the Strongback has lifted approximately 24 " above the forward Vee blocks. Release SW11. See step 5.1.5.8 for Elevation Angle indicator checkout.

5.4.5.6.5 Set the STRONGBACK DIRECTION switch (SW12) to the LOWER position.

5.4.5.6.6 Press the STRONGBACK MOTION switch (SW11). Hold SW11 depressed until the top end of the Strongback has returned to its full down position. DS11 (STRONGBACK DOWN) shall illuminate. Release SW11.

\subsubsection{Leveling}

Located on the trailer bed are two cross axis level sensors, one at the forward end and one at the aft end. Both are located above the jack slide tubes to provide a solid reference. Individual readout devices are located in the IR control box. The readout devices are powered by standard $9 \mathrm{~V}$ Alkaline batteries. On the right-hand end of each readout are two knobs, ZERO and POWER. The ZERO has a "calibrated" sticker attached to it, it is locked in place and cannot be moved. The other is the power ON/OFF switch. Rotate this CW to turn the device $O N$ and $C C W$ to turn it OFF.

These indicators provide side to side leveling indication only. 
Operation and Maintenance Manual Revision A

5.4.5.7.1 Set the POWER switch on both of the LEVEL SENSOR Readouts to the ON position.

5.4.5.7.2 Following the procedures in section 5.1.5.2, lower the jacks until the pads touch the ground.

5.4.5.7.3 observe the readings of the two levels. Adjust the jacks individually until both displays indicate 0.0 .

5.4.5.7.4 Set the JACK SELECT switch to ALL and raise the trailer. The indication on both readouts should remain at zero.

5 4 5.7.5 Return the jacks to their transport positions. Set the display POWER switch to its OFF position.

5.4.6 Elevation Angle Indicator

Located on the Roadside lower end of the Strongback is an angular position sensor. The readout device for this sensor is located in the IR control box. The readout device is powered by a standard $9 V$ Alkaline battery. On the right-hand end of the readout are two knobs, ZERO and POWER. The ZERO has a "calibrated" sticker attached to it, it is locked in place and cannot be moved. The other is the power ON/OFF switch. Rotate this CW to turn the device $O N$ and $\mathrm{CCW}$ to turn it OFF.

5.4.6.1 Set POWER switch on the ANGLE SENSOR Readout to the ON position.

5.4.6.2 Raise the Strongback as in section 5.1.5.6. At the position indicated in step 5.1.5.6.4, the readout will indicate approximately 3.0 degrees.

5.4.6.3 Return the Strongback to its full down position. Set the display POWER switch to its OFF position.

\subsubsection{Video Systems}

The Receiver Trailer is equipped with two separate Video Systems. One system is an adaptation of a standard RV backing system. The other Video System is used during the process of handling the LLCE and consists of a camera located at the top of the Strongback directed at the hook intercept area and a Pan/Tilt controllable camera located at the rear of the trailer. 
Operation and Maintenance Manual Revision A

\subsubsection{LLCE Handling Video System}

5.4.7.1.1 Setup the Monitor Stand that includes the 12" B\&W monitor, Video Source Selector switch and the Pan/Tilt controller.

5.4.7.1.2 Connect the Monitor Stand to a source of 120VAC power. One of the utility receptacles located around the periphery of the trailer can be used.

5.4.7.1.3 Connect the two BNC connector terminated cables between the Control Box (J8 \& J10) to the Monitor Stand (J9 \& J11).

5.4.7.1.4 Connect the Pan/Tilt Control Cable between the Control Box (J12) and the Monitor Stand (J13).

5.4.7.1.5 Set the monitor power switch to its ON position.

5.4.7.1.6 Select video source A with the Video Source Selector switch. Video from the Hook Intercept camera will appear on the monitor screen. If additional light is required, set the light switch located on the exterior of the Control Box to its ON position.

5.4.7.1.7 Select video source B with the Video Source Selector switch. Video from the Pan/Tilt camera will appear on the monitor screen.

5.4.7.1.8 Using the Pan/Tilt Joy Stick Control, move the camera through its range of motion.

5.4.7.1.9 Use the Focus Control to focus the lens on an object. Use the ZOOM control to change from telephoto to wide angle views.

5.4.7.1.10 Set Monitor power switch to OFF. Disconnect and stow Video and Pan/Tilt Control cables.

\subsubsection{IR Remote Control Startup}

The IR (InfraRed) control provides a means of controlling the functions of the trailer at a distance of approximately 150 feet from the trailer. The transmission of the IR beam is strictly line-of-sight, therefore location and direction of the transmitter is important. There are $5 \mathrm{IR}$ receivers located on the trailer, (2) each on the roadside/curbside and one at the rear of the trailer. 
Operation and Maintenance Manual Revision A

The IR control parallels the functions of the Pendant control.

5.4.8.1 In the IR Control box, set the RADIO/PENDANT switch to the RADIO position.

5.4.8.2 On the IR Transmitter box, Insert the key that is attached to the carrying handle into the key switch marked POWER. Turn key fully clockwise.

5.4.8.3 Press the Press-To-Test BATTERY TEST light located next to the switch. The lamp should illuminate.

5.4.8.4 Press the green START button on the transmitter.

5.4.8.5 The upper Green LED on the Processor Card will illuminate. Each time a control on the IR Transmitter is activated, the second Green LED on the Processor Card will flash. A Red LED on the Transmitter array will also flash indicating that a data stream is being transmitted.

5.4.8.6 On the front panel of the right hand control box, press the green CONTROL ENABLE button. The Green POWER ON lamp will light.

5.4.8.7 IR Remote Control Function Checkout

5.4.8.7.1 Under Carriage - Lock / Release

5.4.8.7.1.1 With the hydraulic system running, lift and move the LOCK/RELEASE switch to the LOCK position. Observe that the undercarriage locking cylinder extends.

5.4.8.7.1.2 Release the LOCK/RELEASE switch. Movement of the locking cylinder will stop.

5.4.8.7.1.3 Lift and move the LOCK/RELEASE switch to the RELEASE position. Observe that the undercarriage locking cylinder retracts. Release the LOCK/RELEASE switch.

\subsection{LEVEL - UP/DOWN \& JACK SELECT}

5.4.8.7.2.1 Move the JACK SELECT switch to the RF position (Right or Curbside Front). Press the JACK SELECT ENABLE button. 
Operation and Maintenance Manual Revision A

5.4.8.7.2.2 Lift and move the LEVEL switch toward the DOWN position. The jack at the curbside front of the trailer will move up toward its transport location.

5.4.8.7.2.3 Repeat steps 5.1.7.2.1 through 5.1.7.2.2 for the LF (Roadside Front), RR (Curbside Rear), LR (Roadside Rear) and ALL positions. The JACK SELECT ENABLE button must be pressed each time the JACK SELECT switch position is changed.

\subsection{SLIDE - LEFT/RIGHT \& SLIDE SELECT}

5.4.8.7.3.1 Check that both Front and Rear cross slide tubes are in their centered position.

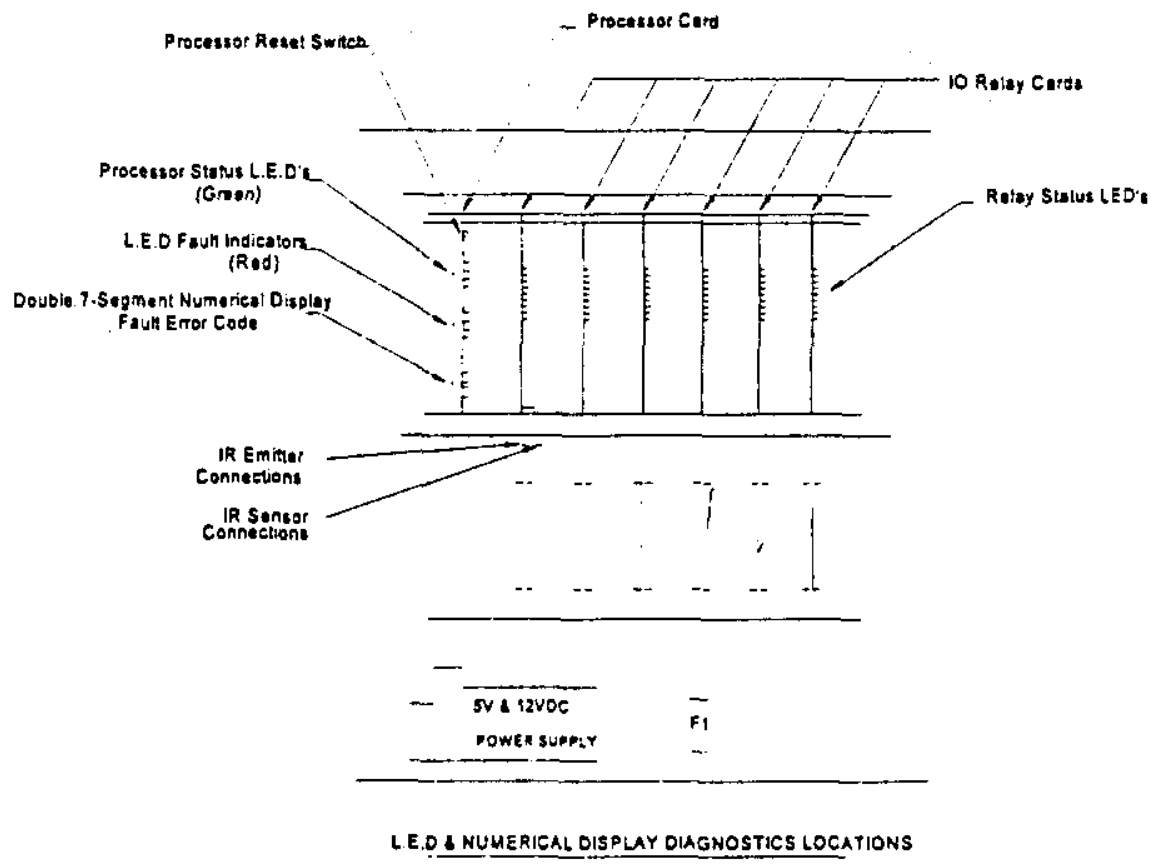


Operation and Maintenance Manual Revision A

\section{NOTE}

Leveling/lifting jacks must be in such a position as to have the wheels of the undercarriage off the ground during this test sequence.

5.4.8.7.3.2 Set SLIDE SELECT switch to the FRONT position. Press the SLIDE SELECT ENABLE button.

5.4.8.7.3.3 Lift and move the SLIDE switch to the LEFT position. The FRONT cross slide motor will operate.

5.4.8.7.3.4 Set SLIDE SELECT switch to the REAR position. Press the SLIDE SELECT ENABLE button.

5.4.8.7.3.5 Lift and move the SLIDE switch to the RIGHT position. The REAR cross slide motor will operate.

5.4.8.7.3.6 Using the SLIDE controls, return the trailer to its centered position.

5.4.8.7.3.7 Set SLIDE SELECT switch to the ALL position. Press the SLIDESELECT ENABLE button.

5.4.8.7.3.8 Lift and move the SLIDE switch to the RIGHT position. Both the FRONT and REAR cross slide motors will operate.

5.4.8.7.3.9 Lift and move the SLIDE switch to the LEFT position. Both the FRONT and REAR cross slide motors will operate. Return the trailer to its centered position.

\subsection{STRONGBACK MOTION \& STRONGBACK DIRECTION - UP/DOWN}

5.4.8.7.6. 1 All four leveling jacks must be down and the trailer brought into a level condition. See step 5.1.5.7 for leveling instructions. The TUG must be in its parked position.

5.4.8.7.6.2 Start the Hydraulic Power Supply by pressing the HYDRAULIC PUMP START switch (SW 15). Both DS4 (HYDRAULIC PUMP \#1 RUNNING) and DS5 (HYDRAULIC PUMP \#2 RUNNING) on the control box shall illuminate. 
Operation and Maintenance Manual

Revision A

5.4.8.7.6.3 Lift and move the STRONGBACK DIRECTION switch to the RAISE position. Hold STRONGBACK DIRECTION switch in this position until the top end of the Strongback has lifted approximately 24" above the forward . Vee blocks. Release STRONGBACK DIRECTION switch. See step 5.1.5.8 for angular position indication.

5.4.8.7.6.4 Lift and move the STRONGBACK DIRECTION switch to the LOWER position. Hold STRONGBACK DIRECTION switch in this position until the top end of the Strongback has returned to its full down position. DS11 (STRONGBACK DOWN) shall illuminate. Release STRONGBACK DIRECTION switch.

\subsection{E-STOP}

5.4.8.7.7.1 Press the red E-STOP button on the IR transmitter. KEPO will drop out and stop all control action.

NOTE

The E-STOP. switch does NOT disconnect AC power from the Control Box.

5.4.8.7.7.2 Press the CONTROL ENABLE switch to restore control.

\subsection{STEERING RIGHT/LEFT}

The Steering controls are located only on the IR Transmitter. The intended function of this system is to enable personnel in a chase vehicle to steer the rear end of the trailer around tight corners.

For normal transit the undercarriage must be restrained in a centered condition. At the forward end of the front undercarriage assembly is a lunette eye that is extended to mate with the hook mounted to the frame. The locking bar must be connected to the hook during transit.

During operations where an LLCE is being handled, the locking bar must be in the fully retracted position. There is a locking pin that also must be inserted in the locking bar to retain it in its retracted position. An additional interlock is provided by a switch that senses the position of the bar. This switch must be actuated before the steering system will operate. 
Operation and Maintenance Manual Revision A

\subsection{Start Generator per section 5.1.2.}

Open the door on the left hand control cabinet.

5.4.8.7.8.2 Set Power Source select switch (TRSW1) to position 2 (Generator).

5.4.8.7.8.3 Set the generator Circuit Breaker, CB2, to its ON position.

5.4.8.7.8.4 Set the Main Circuit Breaker, CB1, to its ON position. If CB1 has been tripped by the Shunt Trip circuit, the breaker handle will have to be moved to its OFF position, then to the ON position. This will reset the Shunt Trip.

\subsection{Set MSP1 to its ON position.}

5.4.8.7.8.6 Set MSP2 to its OFF position. The generator is not able to operate both hydraulic pumps at the same time. Either pump \#1 or \#2 may be operated for this function (interchange references to MSP1 \& MSP2).

5.4.8.7.8.7 Set $C B 3$ and $C B 4$ to their $O N$ positions.

Open the door of the right hand control box.

5.4.8.7.8.8 Set $C B 7$ and $C B 8$ to their ON positions.

Open the door of the IR control cabinet.

5.4.8.7.8.9 Set the RADIO/PEND. Switch to the RADIO position.

Locate the IR Control Transmitter for the Receiver Trailer.

5.4.8.7.8.10 Insert the key that is attached to the carrying handle into the key switch marked POWER. Turn key fully clockwise.

5.4.8.7.8.11 Press the Press-To-Test BATTERY TEST light located next to the switch. The lamp should illuminate.

5.4.8.7.8.12 Press the green START button on the transmitter.

5.4.8.7.8.13 Release the pintle hook latch on the undercarriage and move the lunette eye to its stowed position. 
Operation and Maintenance Manual Revision A

5.4.8.7.8.14 On the curbside of the Receiver Trailer undercarriage, set thehydraulic equalization valve to its OFF position.

5.4.8.7.8.15 On the front door of the lefthand control box, press the CONTROL ENABLE button. The green POWER ON light should illuminate.

5.4.8.7.8.16 On the front of the lefthand control box, press the HYDRAULIC PUMP START button. Hydraulic pump \#1 should start. If MSP2 is selected in step 5.1.7.8.5, pump \#2 will start.

5.4.8.7.8.17 On the IR transmitter, briefly place the STEERING switch in the LEFT position, the front undercarriage assembly should move slightly toward the left. To move the switch from its center position, it is necessary to lift up on the switch before moving it toward the left or right.

\section{NOTE}

For the purposes of a functional check, it is only necessary to bump the undercarriage in each direction. It is not recommended to attempt to steer the undercarriage unless the trailer is in motion.

5.4.8.7.8.18 Begin moving the trailer in either the forward or reverse direction. Movement should be as slow as practical since the steering does not react quickly.

5.4.8.7.8.19 While the trailer is in motion, steer the undercarriage as necessary to accomplish the turn.

5.4.8.7.8.20 Once the turn has been made, the undercarriage must be returned to Its center position. It may be necessary to continue forward motion in order to get the undercarriage running straight. When the undercarriage is straight, reconnect the lunette eye to the pintle hook.

5.4.8.7.8.21 On the IR transmitter, turn the key to the OFF position. Remove key from switch.

5.4.8.7.8.22 On the front door of the lefthand control box, press the EPO switch.

5.4.8.7.8.23 Shut down the generator. 
Operation and Maintenance Manual

Revision A

5.4.8.7.8.24 On the curbside of the Receiver Trailer undercarriage, set thehydraulic equalization valve to its $\mathrm{ON}$ position.

5.4.

All electrical control functions have been checked, the Receiver Trailer is now ready for operational use.

To prepare the Receiver Trailer for the specific piece of LLCE that will be handled the correct skid/burial container combination must be selected and installed on the trailer.

5.5 Transport Trailer System Checkout

This section can be completed in parallel with the Receiver trailer check out/setup section 5.4 .

5.5.1 Shore Power Connection/Test

5.5.1.1 Unstow and connect Shore Power Cable to 12 on Control Box 1 .

\section{NOTE}

The entire 200 foot length of the power cable must be removed from the cable reel. Provision has been made on the shore end of the cable for pulling by a vehicle.

5.5.1.2 Connect Shore Power Cable to source of 480VAC Delta, 3 Phase 3 Wire and Ground.

5.5.1.3 Set Power Source Selector Switch (TRSW1) to the SHORE position (position 1).

5.5.1.4 Set the Shore Power source to its ON position.

5.5.1.5 Set CB1, Located in Control Box 1 to its ON position. CB1 Shall remain in Its $O N$ position. 
Operation and Maintenance Manual Revision A

\section{NOTE}

If $\mathrm{CB} 1$ does not remain in its $\mathrm{ON}$ position, it is an indication that the input phasing is incorrect. To correct a phasing problem any two of the input phases must be interchanged. A qualified electrician familiar with the site power system should make the correction.

5.5.1.6 In Control Box 1, set circuit breakers $\mathrm{CB} 3$ and $\mathrm{CB} 4$ to their $\mathrm{ON}$ positions. CB3 provides Control Power via T1. CB4 provides $120 \mathrm{~V}$ utility power via T2.

5.5.1.7 In Control Box 2 set the Utility Power circuit breakers CB17 through CB20, $\mathrm{CB} 23$ and $\mathrm{CB} 24$ to their $\mathrm{ON}$ positions.

\begin{tabular}{|c|c|c|}
\hline Ref. & Type & Function \\
\hline CB1 & 125A 3 Pole & MAIN INPUT \\
\hline CB2 & 30A 3 Pole & GENERATOR \\
\hline CB3 & 15 A 2 Pole & CONTROL POWER TRANSFORMER \\
\hline CB4 & $40 A$ 2 Pole & UTILITY POWER TRANSFORMER \\
\hline CB5 & $15 \mathrm{~A} 1$ Pole & UTILITY RECEPTACLES \\
\hline CB6 & $15 \mathrm{~A} 1$ Pole & SPARE \\
\hline CB7 & $15 \mathrm{~A} 1$ Pole & HYDRAULIC SUMP HEATER \\
\hline CB8 & $15 \mathrm{~A} 1$ Pole & IR CONTROL \\
\hline CB9 & $15 \mathrm{~A} 1$ Pole & CABINET LIGHT \\
\hline CB10 & $15 \mathrm{~A} 1$ Pole & HEAT EXCHANGER \\
\hline CB11 & $60 \mathrm{~A} 2$ Pole & WELDER RECEPTACLE \\
\hline
\end{tabular}

5.5.1.8 Press CONTROL POWER ENABLE switch SW2 located on the front door of Control Box 2. POWER ON lamp, PL1, on the pendant control shall illuminate.

\subsubsection{Pendant Control Connection}

5.5.2.1 Unstow and connect the pendant control station to $\mathrm{J} 1$ on Control Box 1 . 
Operation and Maintenance Manual

Revision A

5.5.2.2 Set CB3, also located in Control Box 1, to its ON position.

POWER ON lamp, DS1 located on the door of Control Box 2 shall illuminate.

\subsubsection{Pendant Control Function Checkout}

Press the CONTROL ENABLE switch (SW2) on the front of Control Box 1. The green POWER ON lamp on the pendant shall illuminate.

\subsubsection{Undercarriage - Lock / Release}

\section{Note:}

In order to not risk damaging the equipment due to low temperatures, it is necessary to heat the hydraulic oil prior to use. The system does have a heater for this purpose, however it does take a fair amount of time to arrive at the proper temperature. The recommended operating temperature for the oil is approximately $90 \mathrm{deg} . \mathrm{F}$. A thermometer is built into the system for monitoring. If time is of the essence, both hydraulic pumps can be used to also heat the oil, provided the oil temperature is $\mathbf{5 0}$ degrees $\mathrm{F}$ or above.

5.5.3.1.1 With the hydraulic system running, turn the LOCK/RELEASE switch (SW4) to the LOCK position. Observe that the undercarriage locking cylinder extends.

5.5.3.1.2 Release the LOCK/RELEASE switch. Movement of the locking cylinder will stop.

5.5.3.1.3 Turn the LOCK/RELEASE switch (SW4) to the RELEASE position. Observe that the undercarriage locking cylinder retracts. Release the LOCK/RELEASE switch.

5.5.3.2 Level - Up / Down \& Jack Select

5.5.3.2.1 Move the JACK SELECT switch (SW6) to the RF (Right or Curbside Front). 
Operation and Maintenance Manual Revision A

5.5.3.2.2 Turn the LEVEL switch toward the DOWN position. The jack at the curbside front of the trailer will move up toward its transport location and will stop when it trips the Down Limit LS2. Briefly turn the LEVEL switch to the UP position to back the jack off the limit.

5.5.3.2.3 Move the JACK SELECT switch (SW6) to the RF (Right or Curbside Front).

5.5.3.2.4 Turn the LEVEL switch toward the UP position. The jack at the curbside front position on the trailer will begin to move toward the ground (moving the trailer in an upward direction). Hold the switch in the UP position until the footpad of the jack reaches the ground.

5.5.3.2.5 Move the JACK SELECT switch (SW6) sequentially to the LF, RR and LR positions and repeat step 5.2.5.2.4 at each position.

5.5.3.2.6 Move the JACK SELECT switch (SW6) to the ALL position.

5.5.3.2.7 With the hydraulic system running, turn the LOCK/RELEASE switch (SW4) to the LOCK position. Hold the switch in LOCK position until the undercarriage locking cylinder extends to touch the pad on the trailer frame.

5.5.3.2.8 Turn the LEVEL switch toward the UP position. ALL four of the jacks will drive, lifting the trailer. Raise the trailer until the wheels are off the ground.

5.5.3.2.9 Set the JACK SELECT switch to its OFF position. This switch must be in the OFF position to enable any other functions on the pendant control.

\subsubsection{Slide - Left / Right \& Slide Select}

The SLIDE function of the Transport trailer allows independent motion of the Front and Rear cross slides.

The slide function is limited to movement of \pm 3 inches from a centered position. The centered position is indicated by a color band on the cross slides.
5.5.3.3.1 Check that both Front and Rear cross slide tubes are in their centered position.


Operation and Maintenance Manual Revision A

\section{NOTE}

Leveling/lifting jacks must be in such a position as to have the wheels of the undercarriage off the ground during this test sequence.

5.5.3.3.2 Set SLIDE SELECT switch (SW7) to the FRONT position.

5.5.3.3.3 Turn the SLIDE switch (SW8) to the LEFT position. The FRONT cross slide motor will operate as long as SW8 is held in position or until the slide direction limit is reached.

5.5.3.3.4 Turn the SLIDE switch (SW8) to the RIGHT position. The FRONT cross slide motor will operate as long as SW8 is held in position or until the slide direction limit is reached.

5.5.3.3.5 Set SLIDE SELECT switch (SW7) to the REAR position.

5.5.3.3.6 Turn the SLIDE switch (SW8) to the LEFT position. The REAR cross slide motor will operate as long as SW8 is held in position or until the slide direction limit is reached.

5.5.3.3.7 Turn the SLIDE switch (SW8) to the RIGHT position. The REAR cross slide motor will operate as long as SW8 is held in position or until the slide direction limit is reached.

5.5.3.3.8 Set SLIDE SELECT switch (SW7) to the ALL position.

5.5.3.3.9 Turn the SLIDE switch (SW8) to the LEFT position. Both the FRONT and REAR cross slide motors will operate as long as SW8 is held in position or until the slide direction limit is reached.

\subsubsection{Strap Latch / Release}

5.5.3.4.1 With the hydraulic power supply operating, set the STRAP LATCH/RELEASE switch to the RELEASE position. The latch cylinders will move to their retracted position.

5.5.3.4.2 When th STRAP LATCH/RELEASE switch is released it will cut off hydraulic pressure to the cylinders and the internal spring will force the cylinders to the latched position. 
Operation and Maintenance Manual Revision A

\subsubsection{IR Remote Control Startup}

The IR (InfraRed) control provides a means of controlling the functions of the trailer at a distance of approximately 150 feet from the trailer. The transmission of the $\mathbb{R}$ beam is strictly line-of-sight, therefore location and direction of the transmitter is important. There are $5 I R$ receivers located on the trailer, two each on the roadside and curbside and one at the rear of the trailer.

The IR control parallels the functions of the Pendant control.

5.5.4.1 In the IR Control box, set the RADIO/PENDANT switch to the RADIO position.

5.5.4.2 On the IR Transmitter box, Insert the key that is attached to the carrying handle into the key switch marked POWER. Turn key fully clockwise.

5.5.4.3 Press the Press-To-Test BATTERY TEST light located next to the switch. The lamp should illuminate.

5.5.4.4Press the green START button on the transmitter.

5.5.4.5 The upper Green LED on the Processor Card will illuminate. Each time a control on the IR Transmitter is activated, the second Green LED on the Processor Card will flash. A Red LED on the Transmitter array will also flash indicating that a data stream is being transmitted.

5.5.4.6 On the front panel of the right hand control box, press the green CONTROL ENABLE button. The Green POWER ON lamp will light. 
Operation and Maintenance Manual Revision A

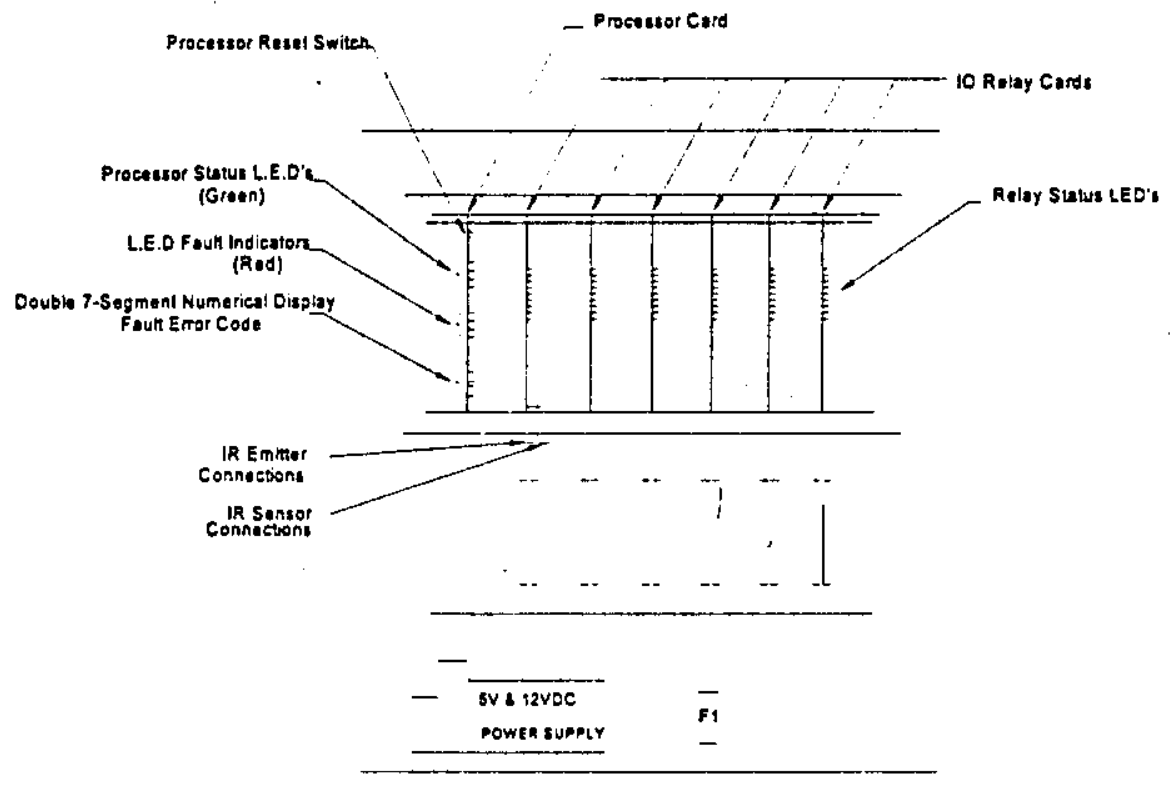

L.E.O \& NUMERICAL OISPLAY DIAGNOSTICS LOCATIONS

\subsubsection{IR Remote Control Function Checkout}

5.5.5.1 Undercarriage - Lock / Release

5.5.5.1.1 With the hydraulic system running, lift and move the LOCK/RELEASE switch to the LOCK position. Observe that the undercarriage locking cylinder extends.

5.5.5.1.2 Release the LOCK/RELEASE switch. Movement of the locking cylinder will stop.

5.5.5.1.3 Lift and move the LOCK/RELEASE switch to the RELEASE position. Observe that the undercarriage locking cylinder retracts. Release the LOCK/RELEASE switch.

5.5.5.2 Level - Up / Down \& Jack Select 
Operation and Maintenance Manual Revision A

5.5.5.2.1 Move the JACK SELECT switch to the RF position (Right or Curbside Front). Press the JACK SELECT ENABLE button.

5.5.5.2.2 Lift and move the LEVEL switch toward the DOWN position. The jack at the curbside front of the trailer will move up toward its transport location.

5.5.5.2.3 Repeat steps 5.2.7.2.1 through 5.2.7.2.2 for the LF (Roadside Front), RR (Curbside Rear), LR (Roadside Rear) and ALL positions. The JACK SELECT ENABLE button must be pressed each time the JACK SELECT switch position is changed.

5.5.5.3 Slide - Left / Right \& Slide Select

5.5.5.3.1 Check that both Front and Rear cross slide tubes are in their centered position.

\section{NOTE}

Leveling/lifting jacks must be in such a position as to have the wheels of the undercarriage off the ground during this test sequence.

5.5.5.3.2 Set SLIDE SELECT switch to the FRONT position. Press the SLIDE SELECT ENABLE button.

5.5.5.3.3 Lift and move the SLIDE switch to the LEFT position. The FRONT cross slide motor will operate.

5.5.5.3.4 Set SLIDE SELECT switch to the REAR position. Press the SLIDE SELECT ENABLE button.

5.5.5.3.5 Lift and move the SLIDE switch to the RIGHT position. The REAR cross slide motor will operate.

5.5.5.3.6 Using the SLIDE controls, return the trailer to its centered position.

5.5.5.3.7 Set SLIDE SELECT switch to the ALL position. Press the SLIDE SELECT ENABLE button.

5.5.5.3.8 Lift and move the SLIDE switch to the RIGHT position. Both the FRONT and REAR cross slide motors will operate. 
Operation and Maintenance Manual

Revision A

5.5.5.3.9 Lift and move the SLIDE switch to the LEFT position. Both the FRONT and REAR cross slide motors will operate. Return the trailer to its centered position.

\subsubsection{Strap Latch / Release}

5.5.5.4.1 With the hydraulic power supply operating, set the STRAP LATCH/RELEASE switch to the RELEASE position. The latch cylinders will move to their retracted position.

5.5.5.4.2 When the STRAP LATCH/RELEASE switch is released it will cut off hydraulic pressure to the cylinders and the internal spring will force the cylinders to the latched position.

\subsubsection{Steer Right / Left}

The Steering function is only available on the IR control Transmitter. The only time this function should be used is when the trailer is connected to a tractor and is in motion. Attempting to steer the undercarriage while the trailer is stationary can damage the tires, the undercarriage and the surface the trailer is parked on. Steer the unit into position as required.

The intended function of this system is to enable personnel in a chase vehicle to steer the rear end of the trailer around tight corners.

Normally, the trailer will be on generator power when the steering is operated. (The extension cord isn't long enough)

For normal transit the undercarriage must be restrained in a centered condition. At the forward end of the front undercarriage assembly is a bar that is intended to mate with the "Goal Post" mounted to the frame. The locking bar must be trapped by the "Goal Post". during transit.

\subsection{Start Generator per section 5.2.2.}

Open the door on the left hand control cabinet.

5.5.5.5.2 Set power source select switch (TRSW1) to position 2 (Generator). 
Operation and Maintenance Manual Revision A

5.5.5.5.3 Set the generator Circuit Breaker, CB2, to its ON position.

5.5.5.5.4 Set the Main Circuit Breaker, CB1, to its ON position.

5.5.5.5.5 Set MSP1 to its ON position.

5.5.5.5.6 Set $C B 3$ and $C B 4$ to their $O N$ positions

Open the door of the right hand control box.

5.5.5.5.7 Set $C B 7$ and $C B 8$ to their $O N$ positions.

Open the door of the IR control cabinet.

5.5.5.5.8 Set the RADIO/PEND. Switch to the RADIO position.

Locate the IR Control Transmitter for the Transport Trailer.

5.5.5.5.9 Insert the key that is attached to the carrying handle into the key switch marked POWER. Turn key fully clockwise.

5.5.5.5.10 Press the Press-To-Test BATTERY TEST light located next to the switch. The lamp should illuminate.

5.5.5.5.11 Press the green START button on the transmitter.

5.5.5.5.12 On the curbside of the Transport Trailer undercarriage, set the hydraulic equalization valve to its OFF position.

5.5.5.5.13 On the front door of the lefthand control box, press the CONTROL ENABLE button. The green POWER ON light should illuminate.

5.5.5.5.14 On the front of the lefthand control box, press the HYDRAULIC PUMP START button.

5.5.5.5.15 On the IR Transmitter, set the UNDERCARRIAGE LOCK/RELEASE switch to the RELEASE position. The "Goal Post" will retract to its UP position. 
Operation and Maintenance Manual

Revision A

\section{NOTE}

The "Goal Post" must be in its full UP position to enable the STEER RIGHT/LEFT function.

5.5.5.5.16. On the IR transmitter, briefly place the STEERING switch in the LEFT position, the front undercarriage assembly should move slightly toward the left. To move the switch from its center position, it is necessary to lift up on the switch before moving it toward the left or right.

NOTE

For the purposes of a functional check, it is only necessary to bump the undercarriage in each direction. It is not recommended to attempt to steer the undercarriage unless the trailer is in motion.

5.5.5.5.17 Begin moving the trailer in either the forward or reverse direction. Movement should be as slow as practical since the steering does not react quickly.

5.5.5.5.18 While the trailer is in motion, steer the undercarriage as necessary to accomplish the turn.

5.5.5.5.19 Once the turn has been made, the undercarriage must be returned to its center position. It may be necessary to continue forward motion in order to get the undercarriage running straight.

5.5.5.5.20 When the undercarriage is straight, lower the "Goal Post" to trap the locking bar. Set the UNDERCARRIAGE LOCK/RELEASE switch to the LOCK position, the "Goal Post" will lower and trap the locking bar.

5.5.5.5.21 On the IR transmitter, turn the key to the OFF position. Remove key from switch.

5.5.5.5.22 On the front door of the lefthand control box, press the EPO switch.

5.5.5.5.23 Shut down the generator.

5.5.5.5.24 On the curbside of the Transport Trailer undercarriage, set the hydraulic equalization valve to its $\mathrm{ON}$ position. 
Operation and Maintenance Manual Revision A

5.5.5.5.25 Check that all cabinet doors are tightly closed (locked if necessary).

6.0 Operation Sequence of Trailer Systems

6.1 Transport Trailer

6.1.1 Park transport trailer in approximate final location.

6.1.2 Disconnect tractor.

6.1.3 Unstow and connect shore power cable.

6.1.4 Enable shore power source. Either generator or site power. If neither shore source is available, the onboard generator may be used for setup. The caveat is that the leveling jacks must be operated one at a time.

6.1.5 Lower jack pads until they make ground contact. Do not level or raise the trailer on the jacks at this time.

6.2 Receiver Trailer

6.2.1 Park Receiver trailer in its' approximate final location for loading LLCE,

\subsubsection{Disconnect tractor}

6.2.3 Unstow and connect shore power cable.

6.2.4 Enable shore power source. Either generator or site power. If neither shore source is available, the onboard generator may be used for setup. The caveat is that the leveling jacks must be operated one at a time.

\subsubsection{Level trailer}

6.2.6 Raise trailer to operating position. In this case, the trailer only needs to be leveled, the suspension does not need to be off the ground since there is no reason to slide or skew the trailer during this phase of the operation.

6.2.7 Raise Strongback to its vertical position. $\left(90^{\circ}\right)$

6.2.8 Extract LLCE and hook onto Strongback. 
Operation and Maintenance Manual Revision A

6.2.9 Lower Strongback to its horizontal position.

Once the. Strongback returns back to horizontal with the item on board, the crane rigging hook must be removed from the item rigging. To do this, stage the removal person on the deck bridge below the front of the skid. Have the crane operator "slack" his line in order to provide the ability to remove hook from the item. Remove the hook and signal hook up and out of the way.

6.2.10 Disconnect crane hook.

6.2.11 Lower trailer and retract leveling jacks to their transport locations.

6.2.12 Disconnect and stow shore power cable.

6.2.13 Connect tractor and move trailer to the previously selected transfer site.

\subsection{Dock \& Load}

6.3.1 Using the RV camera on the rear of the trailer and any other optical aides, back the Receiver trailer into alignment with the Transport trailer.

The mating of the rear of the trailers is accomplished with the dock bumpers fitting between the vertical tubes on the receiver trailer. The receiver trailer truck driver must watch the video camera provided in order to center the trailers with each other as closely as possible when backing. The dock bumper must be within these vertical tubes.

\subsubsection{Unstow and connect shore power cable.}

6.3.3 Enable shore power source. Either generator or site power. If neither shore source is available, the onboard generator may be used for setup. The caveat is that the leveling jacks must be operated one at a time.

6.3.4 Lower jack pads until they make ground contact. Do not level or raise the trailer on the jacks at this time.

6.3.5 Disconnect the RV Video cable from J7 of the trailer. Disconnect tractor from trailer. 
Operation and Maintenance Manual Revision A

6.3.6 Level the Receiver trailer. Do not raise the Receiver trailer any more than is necessary to obtain a level indication on the indicators located in the IR control box.

6.3.7 Now raise the Transport trailer (all 4 outriggers simultaneously). As the transport trailer is raised, its vertical travel is stopped via limit switches on both sides of the rear end. This area can be monitored via the camera mounted on the rear of the Receiver trailer. Once the rear end is centered sufficiently, the front end of the Receiver trailer must be skewed left or right to get a response from the laser receiver mounted on the receiver front shield. A person may be stationed at the laser on the Transport trailer to stop the rotation of the beam to determine the beam location. To center the rotating beam on the laser receiver, the receiver trailer front end must be moved side-to-side in the proper direction to achieve alignment. If maximum travel is reached on the receiver outriggers and alignment is not achieved, the front of the transport trailer can be moved via the outriggers to assist. The laser receiver on the Receiver trailer front shield has arrow indicators that signal if a left or right movement if required. A flashing light in the middle of the receiver indicates alignment. Once alignment is accomplished with the LASER, the optical scope provided on the laser stand can be used for secondary alignment verification. If both the laser and scope indicate alignment, the insertion of any skid diameter will yield a nominal 2" gap between the skid tubes and the I.D. of the burial container.

\subsubsection{Disconnect tractor}

6.3.3 Unstow and connect shore power cable.

6.3.4 Enable shore power source. Either generator or site power. If neither shore source is available, the onboard generator may be used for setup. The leveling jacks should only be operated one at a time in this mode.

\subsubsection{Level trailer}

6.3.6 Raise trailer to operating position. In this case, the suspension must be locked in order that the trailer may be lifted a minimum distance before the suspension is free of ground contact. The wheels of the trailer must be off the ground before the Slide feature may be used. 
Operation and Maintenance Manual Revision A

6.3.7 Using the laser alignment system, align the Receiver trailer's longitudinal centerline with the Transport trailer's longitudinal centerline. The center lines of both trailers must be in line in order to facilitate the transfer of the skid into the burial container.

\subsubsection{Use the Slide feature to accomplish the alignment.}

\subsubsection{Unlatch the skid from the Strongback.}

To ready the item for installation into the container, the tug must be attached to the skid in order to push it. A ball and hitch arrangement is provided to accomplish this attachment. To make this attachment, lower the ball coupler down to its 5 degree position by unhooking and rehooking the chain provided. The tug is equipped with a "final push jack" which serves to functions. It travels out to couple the tug and skid together, and it makes the final push of the skid into the burial container. To couple the ball coupler to the ball, drive the jack out until coupler/ball alignment is close. Release the coupler chain and let the coupler rest on the ball. Pull back the coupler lock (located on top the unit) as the jack operator creeps further toward the ball. Keep pressure on the coupler until it securely drops over the ball. Release the coupler lock. Now the two horizontal jacks that retain the skid to the Strongback can be pulled out to ready the skid for pushing down line.

Make sure that the horizontal jacks are pulled out before pushing the skid with the tug.

\subsubsection{Rigging Guide, Hook Removal, and Tug Attachment to Skid}

There are a number of activities that occur at the front of the Strongback. All of these activities involve the skid. Rigging guides are wing shaped pieces that are installed to help the crane operator guide the item into the hook intercept "dish" when the Strongback is vertical. The guides create a "V" shape to increase the crane target to approximately 24 " in width. To install these guides, place the $1 / 2$ " thick guide plate on the back side of the $1 / 2$ " thick skid plate. Captive bolts are then put through clearance holes on the skid and threaded into the nuts on the guide plates. Torque these bolts to approximately $30 \mathrm{ft}$. Ibs.

Note

After the Strongback returns to horizontal, the rigging guides must be removed. 
Operation and Maintenance Manual Revision A

6.3.11 Move the tug into transfer position and insert the tongue locking pin to lock the Tug to the Skid.

6.3.12 Move the Tug forward to push the Skid and LLCE into the Burial Container.

6.3.13 When the Tug reaches the aft end of the Receiver trailer it will trip a mechanical latch mechanism (Avis device) to lock the Tug into position for the "final push". (The Avis device is to prevent having to push the load against the winch cables.)

\subsubsection{Safety Plate to Bridge Receiver/Transport Trailers}

A flip-down bridge is provided on the rear of the receiver trailer to bridge the gap between the trailers when mated. This safety bridge can be deployed by simply releasing a slide bolt on each side and letting the ramp fall to the transport deck.

\subsubsection{Skid Final Positioning and Measurement}

In order for the skid to provide enough room for the end cap of the burial container, the distance from the open end of the container to the skid must be held at $13 \mathrm{y} / 2$ ". This dimension is taken from the open end of the container to the protruding eye bolt attached to the item rigging. A measurement of $197 / 8$ " can also be taken from the open end of the container to the $7 \mathrm{ga}$. rolled section on the skid. These dimensions should be $+1 ",-0$.

Important: Once the final positioning of the skid is achieved in the burial container and the Tug's work is done, the Avis clamps must be released. If this is not done prior to moving the Tug back to the front of the trailer, the clamps will be destroyed.

\subsubsection{Remove Skid Common Interface}

An interface is provided that connects the front of the skid with the Strongback front jacks. This assembly is to be reused for each skid insertion. Once the skid has been pushed into the burial container, an extension tool is to be used with an impact wrench to loosen and remove the four (4) bolts that make this attachment. The tool provided has a swivel head on it to allow the removal of the bolts in a tight area. There are two(2) tools 
Operation and Maintenance Manual

Revision A

provided, one for all skids 36 through 72 which have $3 / 4$ " bolts, and one for skid 26 which has $1 / 2$ " bolts.

6.3.17 Retract the tug arm back to its stowed position.

6.3.18 Release the Avis device and return the Tug to its parked position at the forward end of the Receiver trailer.

6.3.19 Lower the Receiver trailer back to the ground and retract the leveling jacks into their transport position.

6.3.20 Connect the tractor and move the Receiver trailer to another location.

\subsubsection{Install Personnel Access Platform}

A personnel platform has been provided for use at the rear of the transport trailer. The platform has a number of features noted below:

1. The platform may be craned into place via four(4) lifting eyes provided on the deck of the platform.

2. The ladder has anti-slip paper applied to each rung for safety.

3. A flip-down ramp is provided for mating to the transport trailer deck. The platform vertical legs must be within 1 " of the dock bumpers in order for the ramp to be used.

4. Wind protection for leak testing the burial container lid seal is provided. The tarp can be moved in and out of its mounts via. Allen head screws to match the distance from the end of the trailer to the seal area. This variable distance is largely due to the thermal expansion and contraction of the burial container.

5. Landing gear legs are installed on each of the four corners to match the level of the transport trailer deck and keep the platform level. Bubble levels are provided to indicate levelness.

6. The weight of the platform complete is approximately $1500 \mathrm{lbs}$. 
Operation and Maintenance Manual

Revision A

\subsubsection{Install Trimmie Tube Funnel Jig}

A .jig has been provide that sets the flexible pipe on the end of the skid at the correct radius from the center of the burial container. This is an important step to insure that the void fill connection can be made with the trimmie tube. This process is obviously done after the skid has been inserted into the burial container and the container lid is being readied for installation. To use the funnel jig, follow these steps:

1. Attach the funnel jig to the burial container with the teeth mechanism on the interior of the container. The two adjustment bolts must be to the outside.

2. Locate the jig vertically in line with the trimmie tube as closely as possible by sight.

3. Tighten the bolts on the outside minimally to insure that the jig will not slip.

4. Now use the jig to clamp the SEG funnel assembly (attached to the flex hose) to the front plate of the skid ( $1 / 2$ " thick). A pipe may be required to align the funnel and the jig pipe cutouts

5. The funnel is now in position to be used in void filling

6. Once the funnel is securely clamped to the skid, remove the funnel jig from the burial container.

\subsubsection{Clean Seal Surface}

\subsubsection{Lift End Cap and Place on Container}

\subsubsection{Inflate Seal to Center}

\subsubsection{Check Fit Trimmie Tube Engagement}

\subsubsection{Weld End Cap Per SEG Instructions}

\subsubsection{Kneel Transport Trailer to 1 Degree}

\subsubsection{Remove Access Platform}

The access platform can be removed by either using a crane with the four (4) lifting eyes or by use of a fork lift. Care must be taken when using a crane not to damage the wind protection shield (made of vinyl). Note that the platform weight is approximately $1500 \mathrm{lbs}$. 
Operation and Maintenance Manual Revision A

\subsubsection{Back Tractor under Transport Trailer and Transport to Trench}

The coupling of the tractor to the trailer is no different than the coupling done throughout the trucking industry. The basic steps for coupling are as follows:

1. Make sure outriggers are up and the trailer weight is carried by the bogey and the front landing gear.

2. Confirm that the 5 th wheel plate on the transport trailer is set at 60 inches to accept the WHC tractor to be used. Note the expected king pin weights noted in section 2.2.3.3.

3. Back the tractor under the 5th wheel of the trailer and couple with the trailer king pin. Note that the spring brakes will be set on the trailer due to lack of air pressure.

4. Apply some forward motion to the tractor to confirm hook-up between the tractor and trailer.

5. Connect the glad hand air lines to the trailer to release the spring brakes.

6. Test brakes with forward motion of tractor.

7. Hook-up is done.

Before transporting the void filled burial container to the trench, a number of cross checks should be considered.

1. The front end restraint chains have been tightened sufficiently.

2. The rigging for the lift beam is hanging over the curbside of the trailer. and can be retrieved from the ground to hook to the crane.

3. The outriggers are in their full up position for maximum ground clearance.

4. The bogey turn system (Infra-red) is working.

5. The power cable has been returned to the cable reel.

6. The generator fuel tank is sufficiently full.

7. Generator batteries are charged.

8. Hydraulic pressure is adequate. 
Operation and Maintenance Manual Revision A

\subsubsection{Lifting Off Burial Container}

The burial container must be lifted per SEG lifting procedures. Note that two cranes are to be used for all containers unless deemed otherwise by WHC personnel. Please refer to SEG manuals for lifting information.

\subsubsection{Releasing Strap Cylinders}

Before the burial container can be lifted off of the burial container chock, the Strap Cylinders must be released. This will allow the straps to be free at one end and therefore allow the container to be lifted free via the lifting beam. The strap cylinders are spring loaded and will extend when there is zero pressure to the cylinder. Once pressure is applied to the cylinder, the pins are drawn out of the keepers and therefore free the strap front the chock. All of the cylinders are on a common pressure feed and will all simultaneously withdraw from the keepers as pressure is applied. A "popping" sound will likely be heard as the straps release from the chock keepers.

\subsection{Maintenance}

In order for the trailer systems to function properly over a long period of time, routine maintenance must be done on a number of individual pieces and assemblies. Below are the list of maintenance items, the description of the maintenance, and the frequency.

\subsection{Scheduled Maintenance Items Table}

\subsubsection{Receiver Trailer}

\begin{tabular}{|c|l|l|c|}
\hline $\begin{array}{c}\text { Maint. } \\
\text { Number }\end{array}$ & $\begin{array}{c}\text { Description of } \\
\text { Maint. Item }\end{array}$ & Maintenance to be Performed & $\begin{array}{c}\text { Frequency of } \\
\text { Maintenance }\end{array}$ \\
\hline 1 & $\begin{array}{l}\text { Outrigger } \\
\text { horizontal tubes }\end{array}$ & $\begin{array}{l}\text { Grease with lithium based } \\
\text { grease (fittings on top of tubes) }\end{array}$ & $\begin{array}{c}\text { Once per } \\
\text { month }\end{array}$ \\
\hline 2 & $\begin{array}{l}\text { Outrigger screw } \\
\text { jacks }\end{array}$ & Per Duff Norton Literature & \\
\hline 3 & $\begin{array}{l}\text { Strongback base } \\
\text { wheels }\end{array}$ & $\begin{array}{l}\text { Grease with Amsoil lithium } \\
\text { based grease }\end{array}$ & $\begin{array}{c}\text { Once per } \\
\text { month }\end{array}$ \\
\hline
\end{tabular}


Operation and Maintenance Manual Revision A

\begin{tabular}{|c|c|c|c|}
\hline 4 & $\begin{array}{l}\text { Strongback } 45 \\
\text { degree wheels }\end{array}$ & $\begin{array}{l}\text { Grease with Amsoil lithium } \\
\text { based grease }\end{array}$ & $\begin{array}{c}\text { Once per } \\
\text { month }\end{array}$ \\
\hline 5 & Tug Jack & Per Duff Norton Literature & \\
\hline 6 & Tug "V" wheels & $\begin{array}{l}\text { Grease with lithium based } \\
\text { grease }\end{array}$ & $\begin{array}{l}\text { Once per } \\
\text { month }\end{array}$ \\
\hline 7 & $\begin{array}{l}\text { Tug winch } \\
\text { sheaves }\end{array}$ & $\begin{array}{l}\text { Grease with Amsoil lithium } \\
\text { based grease }\end{array}$ & $\begin{array}{l}\text { Once per } \\
\text { month }\end{array}$ \\
\hline 8 & Winch assembly & Per Thern Literature & \\
\hline 9 & $\begin{array}{l}\text { Jacks at front of } \\
\text { Strongback }\end{array}$ & Per Duff Norton Literature & \\
\hline 10 & Tires & $\begin{array}{l}\text { Monitor Air Pressure noted on } \\
\text { the Tire }\end{array}$ & $\begin{array}{c}\text { Once per } \\
\text { month }\end{array}$ \\
\hline 11 & $\begin{array}{l}\text { Air Ride } \\
\text { Suspension }\end{array}$ & Per Manufacturer Literature & \\
\hline 12 & $\begin{array}{l}\text { Undercarriage } \\
\text { Lock Mechanism }\end{array}$ & Per Nelson Mfg. Literature & \\
\hline 13 & $\begin{array}{l}\text { Steering } \\
\text { Cylinders }\end{array}$ & Per Nelson Mfg. Literature & \\
\hline 14 & Generator & Per Manufacturer Literature & \\
\hline
\end{tabular}

\subsubsection{Counterbalance Valves on Main Cylinders}

The most common cause of failure of a Sun Cartridge is dirt in the hydraulic fluid, which can then lodge in the working parts of the cartridge and interfere with operation. Most Sun Cartridges can be cleaned without altering their settings.

To check and clean a cartridge which is not functioning:

1. Carefully de-pressurize the hydraulic system.

2. Remove the cartridge from its cavity. 
Operation and Maintenance Manual Revision A

3. Inspect for visible contaminants and carefully remove obvious particles.

4. Through the nose of the cartridge, manually operate the inner working parts several times. Use a piece of plastic tubing to avoid damaging soft seats, sharp edges, finished surfaces, or the screen protecting the pilot orifice. All parts should move freely. If possible, do this with the cartridge submerged in clean mineral spirits.

5. After "flushing", blow dry with clean filtered air.

6. Replace seals if indicated, using appropriate Sun service kit.

7. Dip the cartridge in clean hydraulic oil and reinstall.

8. If this procedure does not eliminate the problem, replace with a new cartridge.

Note that a source for accurate technical information or assistance is:

Central Hydraulics, Inc.

Dan McCarthy

$414363-5523$

\subsubsection{Transport Trailer}

\begin{tabular}{|c|c|c|c|}
\hline $\begin{array}{l}\text { Maint. } \\
\text { Number }\end{array}$ & $\begin{array}{l}\text { Description of } \\
\text { Maint. Item }\end{array}$ & Maintenance to be Performed & $\begin{array}{l}\text { Frequency of } \\
\text { Maintenance }\end{array}$ \\
\hline 1 & $\begin{array}{l}\text { Outrigger } \\
\text { horizontal tubes }\end{array}$ & $\begin{array}{l}\text { Grease the tubes with lithium } \\
\text { based grease (fittings on top of } \\
\text { tubes) }\end{array}$ & $\begin{array}{l}\text { Once per } \\
\text { month }\end{array}$ \\
\hline 2 & $\begin{array}{l}\text { Outrigger screw } \\
\text { jacks }\end{array}$ & Per Duff Norton Literature & \\
\hline 3 & $\begin{array}{l}\text { Hydraulic } \\
\text { cylinders for } \\
\text { holding burial } \\
\text { container straps }\end{array}$ & Per Manufacturer Literature & \\
\hline 4 & Tires & $\begin{array}{l}\text { Monitor Air Pressure noted on } \\
\text { the Tire }\end{array}$ & $\begin{array}{l}\text { Once per } \\
\text { month }\end{array}$ \\
\hline 5 & $\begin{array}{l}\text { Air Ride } \\
\text { Suspension }\end{array}$ & Per Manufacturer Literature & \\
\hline
\end{tabular}


Operation and Maintenance Manual Revision A

\begin{tabular}{|c|l|l|l|}
\hline 6 & $\begin{array}{l}\text { Undercarriage } \\
\text { Lock Mechanism }\end{array}$ & Per Nelson Mfg. Literature & \\
\hline 7 & $\begin{array}{l}\text { Steering } \\
\text { Cylinders }\end{array}$ & Per Nelson Mfg. Literature & \\
\hline 8 & Generator & Per Manufacturer Literature & \\
\hline
\end{tabular}

Note that a complete maintenance manual is provided for the portions built by Nelson Manufacturing which includes the bogie assemblies and their associated parts primarily.

\subsection{Corrective Maintenance}

Some items may become obsolete or worn out after usage or exposure to the environments. Below is a listing of some items that have this type of potential, and the corrective action that must be taken.

\subsubsection{Tie-down Release Cylinders}

These cylinders are the ones that anchor the strap on the beam side of the Transport trailer. The are hydraulically operated. Note that each hydraulic unit has a breather on the top to provide a means of pressure regulation. This breather may clog after use in the Hanford area due to sand and dust. If the units are clogged, it is advisable to replace the unit in order to not risk contaminating the hydraulic system. Contact MSI to order spare breathers.

\subsubsection{Unfreezing Rusted Metal Parts}

Stainless steel and aluminum were the materials of choice in the construction of the trailers due to the anticipated Washington environment. Steel had to be used in a number of places due to the nature of the part or assembly. If "freezing" of these steel parts should occur due to rusting, it is advisable to use an anti-seize lubricant in an attempt to free the parts. Depending on the severity of the condition, it may be necessary to use a grinder to separate the parts. In either case, the two surfaces should ultimately be cleaned, prepped, and repainted in order to keep this rust condition from resurfacing. 
Operation and Maintenance Manual

Revision A

\subsubsection{Skid Roller Wheels}

Wheel assemblies are provided to keep the skid on the correct axial path for insertion into the burial container. These wheels were provided in steel due to availability at the time of trailer construction. The wheel will rust in the exterior environments and will have to be replaced at some regular interval. The wheels can easily be replaced using an Allen wrench which is on the flat wheel side. When reinstalling the wheel, hand tighten the Allen bolt with a normal length Allen wrench. The depth and position of the wheel will be set automatically.

Skid Guide Wheel Vendor: $\quad \mathrm{PCl}$

Phone:

$1800323-0966$

Part Number of Wheel: $\quad$ PTR -1.50

Nominal Price per Wheel: $\quad \$ 25$

\subsubsection{DeStaco Clamps (Avis Device)}

Clamps are provided at the end of the Receiver trailer that provide a stop for the Tug to push against for final insertion of the skid into the burial container. If the system is operated incorrectly, the clamps will be damaged upon the Tug returning to the front of the trailer. If this should happen, the clamps have been designed to be the weak link in this support mechanism. Four bolts hold the clamps in place (1 clamp per side of the trailer). Simply unbolt the damaged clamp and install the new one.

\subsubsection{Skid Latch Pins}

Two pins are thrown through the removable interface on the front of the skid as the skid is resting on the Strongback. The pins are made of a high strength steel. These pins can be damaged if the Tug attempts to push the skid without these pins withdrawn. If there is any doubt regarding the damage of the pins, they must be replaced as these pins hold the entire weight of the skid when the Strongback is in the upright position. To replace the pins, first remove the shear pins installed through the latch pins. Then, rotate the screw jack in the proper direction to withdraw the screw from the latch pin. The latch pin has a female thread that threads onto the jack screw, and it also has a key that will keep it from rotating. 
Operation and Maintenance Manual Revision A

If the pins need replacing, contact MSI for a detailed drawing and material description.

\subsubsection{Electrical Replacements}

Servicing the electrical systems on these units should only be performed by qualified personnel. These systems carry voltage/current and actuate moving parts that can cause serious and even fatal injuries.

Lock out electrical power, pneumatic and/or hydraulic systems as required per the site/OSHA compliant lock-out/tag-out program.

Disconnect applicable connections to the device in question. Note where each connection point was made. Inspect/repair/replace the device.

Reconnect applicable connections exactly as removed in the previous step. Reapply power and check for proper function.

\subsubsection{Limit Switch Replacements}

If possible, position the assembly so that the limit switch is not in contact with the limit stop. Lock out/tag out potential energy sources. Open back casing and disconnect wiring (be sure to note which wire connects to which terminal point. Remove mounting screws. Disconnect limit switch from conduit. Transfer the limit switch arm to the replacement switch. Reinstall in reverse order.

Reapply power and cycle function to check limit switch. Adjust as necessary.

\subsubsection{General Pressure Gauge Replacement}

Shut off all pressure to gauge by closing the needle valves by the gauge or by shutting down the pump. Be assured that the pressure at the gauge is zero before attempting to remove the gauge. Once the gauge is removed, protect the open gauge port with a clean lint free cloth to preclude dirt from entering the system. Replace the gauge gasket or ring before installation of the new gauge. Make sure that the gauge has the same pressure range as the one that was removed. Also use the literature accompanied by the gauge as a guideline. 
Operation and Maintenance Manual Revision A

\subsubsection{Cameras (Pan and Tilt)}

Camera: Lockout/Tagout potential energy sources. Open environmental housing. Remove connected cabling and wiring (be sure to note connection points). Loosen the two screws holding the mounting plate in the enclosure. Remove the camera with mounting plate. Remove the camera from the mounting plate. Reinstall in reverse order. Reapply power and check operation.

Pan/Tilt: : Lockout/Tagout potential energy sources. Unbolt camera enclosure from assembly. Disconnect the control cable. Unbolt and remove pan/tilt assembly. Reinstall in reverse order.

\subsection{Adjustments and Alignment}

\subsubsection{Laser Alignment System}

The laser mounted on the front of the Transport trailer deck must be rechecked for alignment before its use in aligning the trailers to each other. The laser is aligned to the rear of the Transport trailer deck via a red line painted on the diamond plate floor. To check alignment, slow the rotation speed of the laser down with the knob provided on the forward side of the laser housing. The laser has a visible red beam that can be followed as it travels the length of the Transport trailer deck. As it closes in on the red alignment line, the beam rotation can be stopped for allowing laser adjustment. Make corrections to the beam with one knob on the laser, making notes on how the beam was adjusted for future reference (ie $1 / 4$ turn clockwise, etc.l.

\subsubsection{Secondary Alignment Verification Calibration}

An optical scope is provided on the laser stand to confirm trailer alignment. This scope provides assurance after using the laser alignment that the skid is properly aligned for insertion. Once the laser is used to align the trailers, the scope should provide confirmation of alignment via a bullseye located on the Tug frame. To calibrate the scope, first be assured that the above laser alignment has been done. Then adjust the scope with the simple adjustment screws to hit the center of the bullseye on the Tug frame. 
Operation and Maintenance Manual Revision A

\subsubsection{Tug Winch Cables}

The Tug cables will slacken or stretch after repeated use of the Tug. This slackening does not necessarily lessen the winch capability, but it does create a jerking motion as the skid is being pushed along the Strongback and into the burial container. Repeated rubbing on the trailer deck also may shorten cable life and wear on the deck surface. It will be necessary to tighten the Tug cables once in a while as the cable stretches due to use. When properly stretched, the cables should not touch the deck when the Tug is in the forward position. To tighten the cables, follow the below steps. It is recommended that at least two people do this work.

1. Run the Tug to the forward position on the trailer.

2. Loosen cable connection on the rear side of the Tug via the cable clamps provided. Loosen the cable on both sides of trailer.

3. Shore the cables vertically along the length of the trailer in approximately 4 places to eliminate the majority of the slack before stretching.

4. Pull the loose end of each cable (facing the rear of the trailer) toward the rear, pulling the cable thru the thimble provided at the connection to the Tug. This pulling may be done by hand or with a cable clamp (Chinese web type) to eliminate the majority of the slack. Once it is determined that the cable's slack has been minimized, tighten each of the cable clamps, starting with the clamps closest to the thimble.

\subsubsection{Adjustments for Air Ride Suspension}

See the Nelson Manufacturing portion of this manual.

7.3.5 Hydraulic Pressure Adjustments

See Eagle Equipment Literature attached in Appendix F.

\subsubsection{Valve Positions for Steerable Bogey}


Operation and Maintenance Manual Revision A

\subsubsection{Camera Adjustments}

See Operator's Manual in Appendix G.

\subsubsection{Hydraulic Cylinders (Strongback) Counter Balance Valves}

All Sun cartridges are built with leak proof adjustment "o" ring seals on the adjusting screw, but are not designed for frequent adjustment in the field.

General: The setting of counterbalance valves should be at least 1.3 times the load induced pressure. Counterbalance valves should have pressure adjustments set at the factory, or on a test stand if possible, as it is very hard to know how the valve is set when it is in a circuit.

In general, lower pilot ratios provide better motion control and stability, especially on spongy systems and with high inertial loads.

Counterbalance valve adjustment is achieved by loosening the lock nut, and adjusting the adjustment screw using a 3/16" Allen wrench.

Turn the screw counterclockwise to reduce setting and release load.

Complete adjustment range in 3 turns.

7.4 Calibration Requirements and Procedures

7.4.1 IR Remote Calibration

This is not a field serviceable item. Refer to the Control Chief manual for nearest authorized service center.

\subsection{Trouble Shooting}

8.1 Receiver Trailer

\subsubsection{PROBLEM: NO POWER}

Causes: Main breaker off or defective.

Incorrect input phasing or loss of phase.

Power source selector switch in wrong position. 
8.1.2 PROBLEM: NO CONTROL

Causes: No power.

IR/Local switch in wrong position.

Pendant not connected.

I/R battery packs low.

8.1.3 PROBLEM: UNDERCARRIAGE FUNCTION NOT WORKING

Causes: No supply voltage to pendant.

Pendant switch failure.

Loss of signal through pendant.

Solenoid valve failure.

I/R failure.

Hydraulic failure.

Mechanical failure.

8.1.4 PROBLEM: LEVEL UP/DOWN NOT WORKING

Causes: No supply voltage to pendant.

Pendant switch failure.

Loss of signal through pendant.

Limit switch(es) failure.

Contactor failure or overload trip/failure.

Power failure.

Motor(s) failure.

Underspeed monitor failure.

V/R failure.

Mechanical failure.

8.1.5 PROBLEM: JACK SELECT NOT WORKING

Causes: No supply voltage to pendant.

Pendant switch failure.

Loss of signal through pendant.

Limit switch(es) failure.

Contactor failure or overload trip/failure.

Power failure.

Motor(s) failure.

Underspeed monitor failure

I/R failure.

Mechanical failure. 
8.1.6 PROBLEM: SLIDE NOT WORKING

Causes: No supply voltage to pendant.

Pendant switch failure.

Loss of signal through pendant.

Limit switch(es) failure.

Contactor failure or overload trip/failure.

Power failure.

Motor(s) failure.

Underspeed monitor failure.

I/R failure.

Mechanical failure.

8.1.7 PROBLEM: TUG NOT WORKING

Causes: No supply voltage to pendant.

Pendant switch failure.

Loss of signal through pendant.

Limit switch(es) failure.

Contactor failure or overload trip/failure.

Power failure.

Motor(s) failure.

Overload monitor failure.

I/R failure.

Mechanical failure.

8.1.8 PROBLEM: PUSHER NOT WORKING

Causes: No supply voltage to pendant.

Pendant switch failure.

Loss of signal through pendant.

Limit switch(es) failure.

Contactor failure or overload trip/failure.

Power failure.

Motor(s) failure.

I/R failure.

Mechanical failure.

Connector not plugged in. 


\subsubsection{PROBLEM: STRONG BACK NOT WORKING}

Causes: No supply voltage to pendant.

Pendant switch(es) failure.

Loss of signal through pendant.

Limit switch(es) failure.

Contactor failure or overload trip/failure.

Power failure.

Motor(s) failure.

I/R failure.

Mechanical failure.

8.1.10 PROBLEM: STEERING NOT WORKING

Causes: Limit switch(es) failure.

Solenoid failure.

Power failure.

Motor(s) failure.

I/R failure.

Mechanical failure.

\subsubsection{PROBLEM: HYDRAULICS NOT WORKING}

Causes: Power failure.

Control voltage failure.

Start/Stop switch failure.

Contactor failure.

Overload failure.

Low fluid level.

Low fluid level switch failure.

\subsubsection{PROBLEM: UTILITY FUNCTIONS NOT WORKING}

Causes: Loss of power to CB4.

CB4 OFF or failure.

Transformer failure.

CB7 OFF or failure.

Individual circuit breaker OFF or failure.

Device or wiring failure.

\subsection{Transport Trailer}


8.2.1 PROBLEM: NO POWER

Causes: Main breaker off or defective.

Incorrect input phasing or loss of phase.

Power source selector switch in wrong position.

8.2.2 PROBLEM: NO CONTROL

Causes: No power.

IR/Local switch in wrong position.

Pendant not connected.

I/R battery packs low.

\subsubsection{PROBLEM: UNDERCARRIAGE FUNCTION NOT WORKING}

Causes: No supply voltage to pendant.

Pendant switch failure.

Loss of signal through pendant.

Solenoid valve failure.

I/R failure.

Hydraulic failure.

Mechanical failure.

8.2.4 PROBLEM: LEVEL UP/DOWN NOT WORKING

Causes: No supply voltage to pendant.

Pendant switch failure.

Loss of signal through pendant.

Limit switch(es) failure.

Contactor failure or overload trip/failure.

Power failure.

Motor(s) failure.

Underspeed monitor failure.

I/R failure.

Mechanical failure.

8.2.5 PROBLEM: JACK SELECT NOT WORKING

Causes: No supply voltage to pendant.

Pendant switch failure.

Loss of signal through pendant.

Limit switch(es) failure.

Contactor failure or overload trip/failure.

Power failure.

Motor(s) failure. 
Underspeed monitor failure.

I/R failure.

Mechanical. failure.

8.2.6 PROBLEM: SLIDE NOT WORKING

Causes: No supply voltage to pendant.

Pendant switch failure.

Loss of signal through pendant.

Limit switch(es) failure.

: Contactor failure or overload trip/failure.

Power failure.

Motor(s) failure.

Underspeed monitor failure.

I/R failure.

Mechanical failure.

\subsubsection{PROBLEM: STRAP NOT WORKING}

Causes: No supply voltage to pendant.

Pendant switch failure.

Loss of signal through pendant.

Solenoid failure.

Hydraulic failure.

Mechanical failure.

8.2.8 PROBLEM: STEERING NOT WORKING

Causes: Limit switch(es) failure.

Solenoid failure.

Power failure.

Motor(s) failure.

I/R failure.

Mechanical failure.

8.2.9 PROBLEM: HYDRAULICS NOT WORKING

Causes: Power failure.

Control voltage failure.

Start/Stop switch failure.

Contactor failure.

Overload failure.

Low fluid level.

Low fluid level switch failure. 
Operation and Maintenance Manual Revision A

\subsection{Parts and Materials}

\subsection{List of Major Components and Source}

\begin{tabular}{|c|c|c|c|}
\hline Component & Manufacturer & Vendor Name & $\begin{array}{l}\text { Vendor Phone } \\
\text { and Contact }\end{array}$ \\
\hline Wheel Grease & Amsoil & Amsoil & (715) 392-7101 \\
\hline Screw Jacks & Duff Norton & $\begin{array}{l}\text { Cincinnati Belting } \\
\text { and Transmission }\end{array}$ & $\begin{array}{c}\text { (513) } 621-9050 \\
\text { Fred Harvey }\end{array}$ \\
\hline $\begin{array}{c}\text { Landing Gear } \\
\text { Jacks on Platform }\end{array}$ & Binkley & Binkley & (314) 456-3455 \\
\hline $\begin{array}{c}\text { ISO Castings and } \\
\text { Twistlocks }\end{array}$ & Blair International & Blair International & $\begin{array}{c}\text { (708) } 769-0222 \\
\text { Maria }\end{array}$ \\
\hline $\begin{array}{c}\text { Strongback } \\
\text { Pivot Bearings }\end{array}$ & Dixon & Bearings, Inc. & $\begin{array}{l}\text { (513) } 242-1600 \\
\text { Chuck Hemmerle }\end{array}$ \\
\hline Tug Wheels & McGill & $\begin{array}{l}\text { Cincinnati } \\
\text { Transmission }\end{array}$ & $\begin{array}{c}\text { (513) } 731-5225 \\
\text { Dennis }\end{array}$ \\
\hline $\begin{array}{l}\text { Infrared Control } \\
\text { System }\end{array}$ & Control Chief & Control Chief & $\begin{array}{c}\text { (800) } 233-3016 \\
\text { Larry Glenn }\end{array}$ \\
\hline Hydraulic System & Misc. & Misc. & $\begin{array}{c}\text { (513) } 721-8000 \\
\text { Patt/Don }\end{array}$ \\
\hline Generators & & $\begin{array}{c}\text { Engine Power } \\
\text { Source }\end{array}$ & $\begin{array}{c}\text { (704) } 533-7286 \\
\text { Tommy Danials }\end{array}$ \\
\hline Fuel Tanks & Tempo & Hern Marine & $\begin{array}{c}\text { (513) } 874-2628 \\
\text { Dave }\end{array}$ \\
\hline Storage Boxes & Highway Products & Highway Products & $\begin{array}{c}\text { (800) } 866-5269 \\
\operatorname{Dan}\end{array}$ \\
\hline Cable Reels & Hannay & Hannay Reels & $\begin{array}{c}\text { (518) } 797-3791 \\
\text { Noel Withjack }\end{array}$ \\
\hline Ladders & Denner & Industrial Ladder & $(513) 860-9720$ \\
\hline
\end{tabular}


Operation and Maintenance Manual Revision $\mathrm{A}$

\begin{tabular}{|c|c|c|c|}
\hline $\begin{array}{c}\text { Misc. Rigging } \\
\text { Supplies /Chain, } \\
\text { Wire Rope, } \\
\text { Shackles, etc. }\end{array}$ & $\begin{array}{c}\text { Industrial Wire } \\
\text { Rope }\end{array}$ & $\begin{array}{c}\text { Industrial Wire } \\
\text { Rope }\end{array}$ & $\begin{array}{c}\text { (513) } 941-2443 \\
\text { Scott }\end{array}$ \\
\hline $\begin{array}{c}15 \text { KVA } \\
\text { Transformer }\end{array}$ & $\begin{array}{l}\text { Heavy Duty - } \\
\text { SOLA }\end{array}$ & $\begin{array}{c}\text { Johnson Electric } \\
\text { Supply }\end{array}$ & $\begin{array}{c}\text { (513) } 421-3700 \\
\text { Todd }\end{array}$ \\
\hline $\begin{array}{l}\text { Clinometers, } \\
\text { Angular Position } \\
\text { Indicators }\end{array}$ & Lucas & $\begin{array}{l}\text { Lucas Control } \\
\text { Systems Products }\end{array}$ & $\begin{array}{c}\text { (800) } 745-8008 \\
\text { Sandy Schultz }\end{array}$ \\
\hline $\begin{array}{l}\text { Shielding Hoist } \\
\text { Rings }\end{array}$ & & McMaster Cars & $(708) 833-0300$ \\
\hline $\begin{array}{l}\text { Hydraulic } \\
\text { Cylinders to Lift } \\
\text { the Strongback }\end{array}$ & Mobile Cylinders & Mobile Cylinders & $\begin{array}{l}\text { (414) } 363-5365 \\
\text { Danial McCarthy }\end{array}$ \\
\hline Paint & Amercoat & $\begin{array}{l}\text { Prysock and } \\
\text { Associates }\end{array}$ & $\begin{array}{c}\text { (513) } 793-3784 \\
\text { Les }\end{array}$ \\
\hline Guide Wheels & $\mathrm{PCl}$ & $\mathrm{PCl}$ & $\begin{array}{c}(800) 323-0966 \\
\text { Maureen }\end{array}$ \\
\hline $\begin{array}{l}\text { DeStaco Clamps } \\
\text { for "Avis" feature }\end{array}$ & DeStaco & $\begin{array}{c}\text { Troyan-Kennedy } \\
\text { Co. }\end{array}$ & (513) $874-9300$ \\
\hline AC Power Monitor & TimeMark Corp. & Tech-Line Co. & (513) $528-1288$ \\
\hline Winch & Thern & Thern & $\begin{array}{c}(800) 843-7648 \\
\text { Greg Nyseth }\end{array}$ \\
\hline $\begin{array}{c}\text { Casters, } \\
\text { Strongback Base } \\
\text { and } 45 \text { Degree }\end{array}$ & $\begin{array}{l}\text { Wellington } \\
\text { Industries }\end{array}$ & $\begin{array}{l}\text { Wellington } \\
\text { Industries }\end{array}$ & (513) $825-2300$ \\
\hline Hydraulic Oil & $\begin{array}{c}\text { UNAX } \\
(\text { Unax AW \# 46) }\end{array}$ & $\begin{array}{l}\text { Heyob Oil } \\
\text { Company }\end{array}$ & (513) $367-6868$ \\
\hline
\end{tabular}

